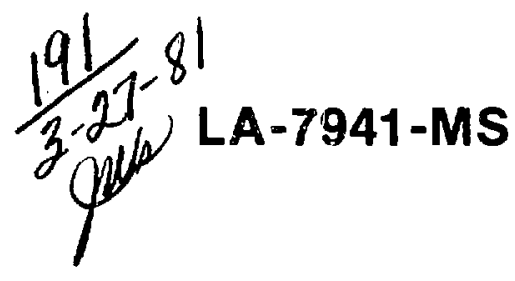

X-Ray Diodes for Laser Fusion

Plasmo Diagnostics

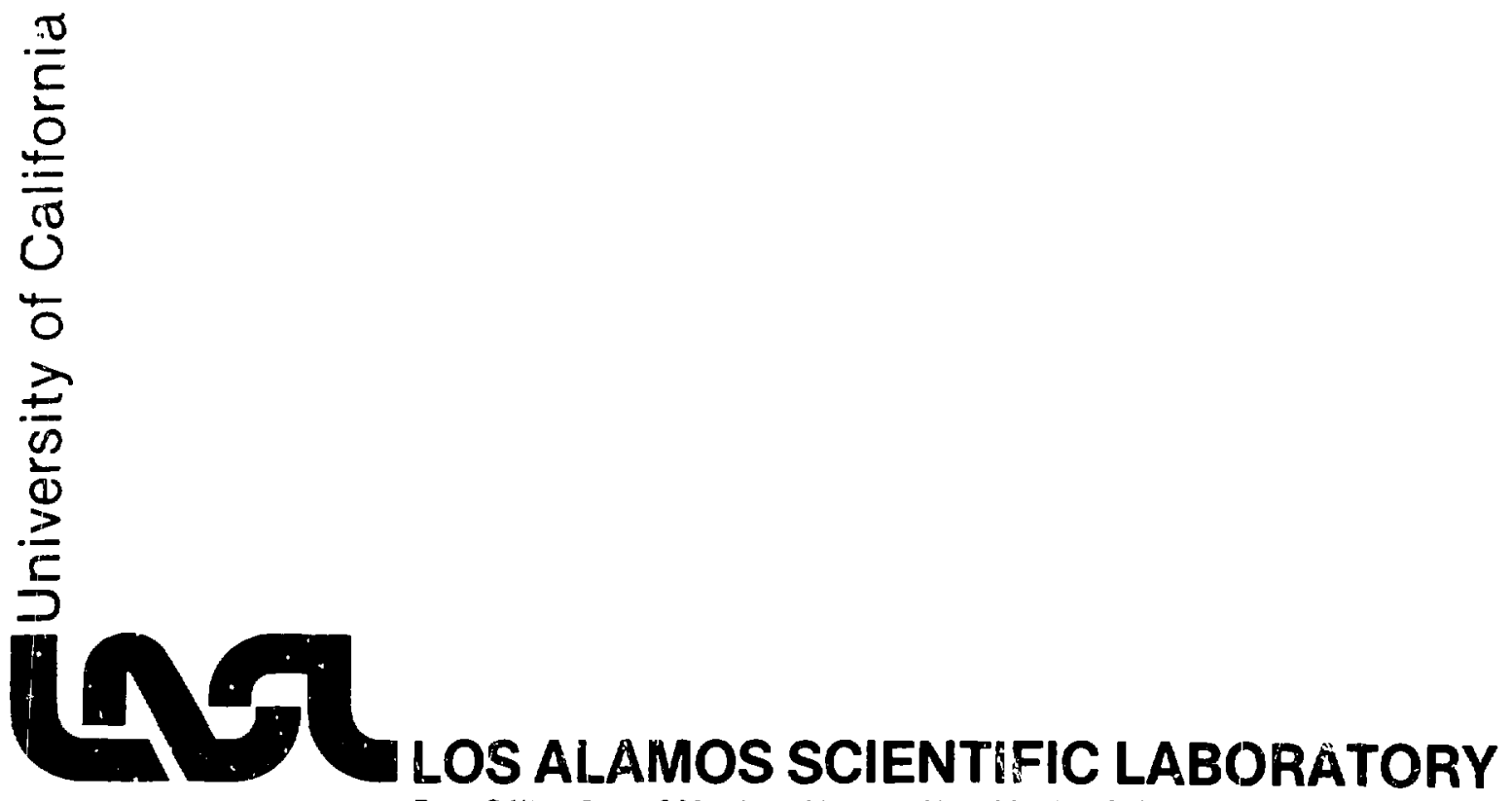




\title{
X-RAY DIODES FOR LASER FUSION PLASMA DIAGNOSTICS
}

\author{
by
}

R. H. Day, P. Lee, E. B. Saloman, and D. J. Nagel

\begin{abstract}
Photodiodes with $x$-ray sensitive photocathodes are commonly used as broadband $x$-ray detectors in fusion plasma diagnostics. We have measured the risetime of the detector system and have measured the quantum efficiency between 1-500 $\mathrm{A}$ of numerous photocathode materials of practical interest. The materials studied include aiuminum, copper, nickel, gold, three forms of carbon, chromium, and cesium iodide. The results of the measurements are compared wirh Henke's semiempirical model of photoyield. We have studied the effects of long-term cathode aging and use as a plasma diagnostic on cathode quantum efficiency. In addition, we have measured the $x$-ray mass-absorption coefficient of several ultrasoft $x$-ray windows in energy regions where data were unavailable. Windows studied were made of aluminum, Formvar, polypropylene, and Kimfoil. Measurements between 1-50 A were performed with the Los Alamos Scientific Laboratory's low-energy $x$-ray calibration facility, and the measurements between 50-550 A were performed at the National Bureau of Standerd's synchrotron ultraviolet radiation facility.
\end{abstract}

\section{INTRODUCTION}

In the laser fusion experimental program at the Los Alamos Scientific Laboratory (LASL), we use $x$-ray diagnostics as a primary means of monitoring the laser-target interaction and subsequent implosion. We measure temporally, spatially, and energy-resolved i rays from the high-temperature plasma. Although we never measure all of these parameters with a single instrument, we do sample a limited region of one or two of these variables with a single detector. Temporal resolution of laser fusion plasmas is particularly difficuit, because the events occur as single pulses that last from a few tens of picoseconds to a nanosecond. To perform high-bandwidth energy-resolved $x$-ray measurements, we developed biplanar $x$-ray sensitive diodes whose signals are recorded with state-of-the-art high-speed oscilloscopes.
Biplanar diodes with $\mathrm{x}$-ray sensitive photocathodes have been used as broadband $x$-ray detectors in several plasma diagnostics applications. ${ }^{1.2}$ An $x$-ray diode (XRD) is shown in Fig. I. It is a simple detector with a
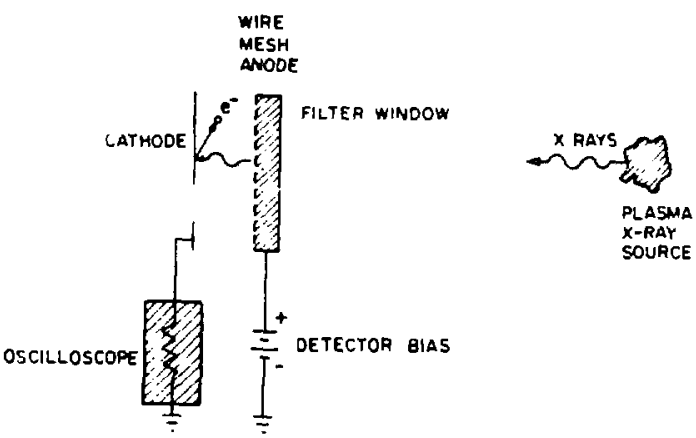

Fig. 1.

A biplans XRD. 
cathode that views the $x$-ray source through a filter window. The anode can be either the filter window, if it has a metallic surface, or a separate wire mesh placed between the window and the cathode.

The detector's energy-dependent response is determined by the photocathode's photoelectric quantum efficiency multiplied by the transmission of the filter window and anode. Typical response curves for an aluminum photocathode with various filter window anodes are shown in Fig. 2. The detector's temporal response is determined by its geometry and the bandwidth of the recording system. We built detectors with a 65 -ps full width at half maximum (FWHM) ${ }^{3}$ and recorded the signals on a $5-\mathrm{GHz}$ bandwidth oscilloscope with a $150-\mathrm{mV} / \mathrm{cm}$ vertical sensitivity. The primary virtues of thes: detectors are their simplicity, speed, and cost while providing moderate energy resolution.

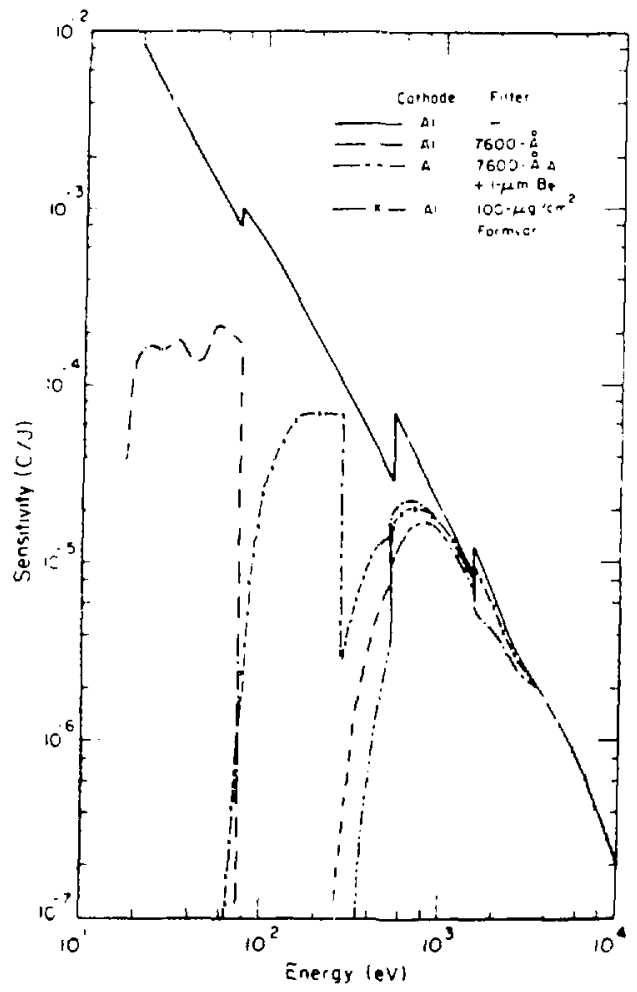

Fig. 2.

Response curve of an aluminum cathode convolved with several filter windows.
To make a useful detector system, it is necessary to know the quantum efficiency of the cathodes and transmission of the filter windows over the energy range of interest, which for us is $10 \mathrm{eV}$ to $10 \mathrm{keV}$. Quantum efficiencies have been measured for many years, but relatively few data are available for cathode materials of practical interest over this extended energy range. Cairns and Samson ${ }^{4}$ surveyed the photoelectric yields of 16 metallic photocathodes from 10 to $60 \mathrm{eV}$. Saloman measured $\mathrm{Al}_{2} \mathrm{O}_{3}$ from 25 to $250 \mathrm{eV}$. Gaines and Hansen ${ }^{6}$ characterized golu from 1.5 to $8 \mathrm{keV}$. and Eliseenko et al. ' measured a numbir of metallic and dielectric photocathodes from 1.2 to $8 \mathrm{keV}$.

Similarly, relatively little data are availabic below 100 $\mathrm{eV}$ on the photoelectric absorption coefficients of most filter window materials. A table of optical constants, including absorption coefficients. on some metals from $10 \mathrm{eV}$ to $10 \mathrm{keV}$ was compiled at the Deutsches Elektronen-Synchrotron (DESY). ${ }^{8}$ Henke and Ebisu ${ }^{4}$ compiled a complete table of absorption coefficients from 100 to $1500 \mathrm{eV}$. Viegele et al. ${ }^{10}$ published a table above $100 \mathrm{eV}$, and several good tables exis: for coefficients above $1 \mathrm{keV}$.11. $^{12}$ To produce a calibrated detec tion system. it is necessary to survey the photoslectric yield from $25 \mathrm{eV}$ to $10 \mathrm{keV}$ of various potential cathode materials and to measure the filter window photoelectric absorption coefficients in regions where data are un available.

In Section II, we describe the XRD's construction and time-response measurements. In Section III. we describe the decector calibration, discuss the results of our cathode quantum efficiency and filter window transmission measurements, and compare our results to a model of total y.eld. ${ }^{13}$ in Section IV, we describe the reproducibility of manufacturing the photocathodes and discuss the effects of aging and the laser fusion experimental environenent on the detector sensitivity. In Section $V$, we show some low-energy $\mathbf{x}$-ray spectra measured on the HELIOS $\mathrm{CO}_{2}$ laser system at LASL. We also show the results of time-resolved $x$-ray measurements from 1 to $5 \mathrm{keV}$ taken with the GEMINI $\mathrm{CO}_{2}$ laser and single- and two-beam Nd-YAG lasers. In Appendix $A$, we present a compilation of our quantum efficiency measurements; Appendix B contains our measurements of filter window photoelectric mass absorption coefficients. 


\section{THE DETECTORS}

\section{A. Construction}

We built XRDs for measuring both time-integrated and time-resolved $x \cdot r a y$ spectra. The first type is a miniaturized four-element $X R D$ array in an $11.43 \mathrm{~cm}$ Conflat ${ }^{*}$ flange. A picture of this detector with the filter window holder renoved is showr in Fig. $3 \mathrm{a}$ and a cross section is shown in Fig. 3b. The cathodes are $1.40 \mathrm{~cm}$-diam metal buttons of the desired material mounted on Berkley Nucleonics Corp. (BNC) vacuum feedthrus. The cathodes are biased negatively at $5001000 \mathrm{~V}$ with respect to the anode and the signals are read through a low-inductance dc isolating capacitor. The time response of these detectors is a 600 -ps FWHM when measured through $3.05 \mathrm{~m}$ of RG 58 cable and the signals are recorded on either a standard $500 \mathrm{MHz}$ laboratory oscilloscope or a fast gated electronic inte. grator.

We built the second type of XRD for time response and mounted the single unit on an $11.43 \mathrm{~cm}$ Conflat flange. The same type of demountable cathode is used as for the slower version XRD. Because the signals are recorded on $5-\mathrm{GHz}$ bandwidth single-shot oscilloscopes. the time response of the detector should be $\leq 65 \mathrm{ps}$, the scope risetime. It should also have a well-matched $50-\Omega$ characteristic impedance to suppress reflections. The detector is shown in Fig. $4 \mathrm{a}$ and a cross section is shown in Fig. 4b. The anode is biased positively with respect to the cathode to remove any coupling capacitors from the signal line that might limit the system bandwidth. The anode also forms a 15-nf capacitor with the XRD housing to store charge and maintain the anode-cathode gap voltage during the first few hundred picoseconds of the $x$-ray pulse. We have added a $0.61-\mathrm{m}$-long. 50- $\Omega$ vacuum transmission line behind the anode to allow at least $4 \mathrm{~ns}$ before the return of any reflections from the vacuum feedthru. The best vacuum feedthru we have found for these frequencies is a nonvacuum General Radio model 874 connector $^{* *}$ sealed with a thin layer of epoxy. Both fast single-pulse and $18-\mathrm{GHz}$ tim:-domain reflectometer (TDR) measurements show that the reflected pulse at the feedthru is less than $3 \%$ of the main puise.

"Conflat is a registered trademark of Varian Associates.

"Manufactured by General Radio Corporation.

\section{B. Time Response}

The detector risetime $t_{r}$. in seconds, is given by the electron flight time across the anode-cathode gap spacing $d$ in meters (Ref. 14):

$t_{t}=\frac{d\left(2 m_{J} / e\right)^{1 / 2}}{V^{1 / 2}}$

where $V$ is the diode bias voltage and $m_{e}$ and $e$ are the electron mass in kilograms and charge in coulombs, respectively. We assume in this derivation that the electrons have zero initial velocity. The detector's fall time $t_{d}$, in seconds, is the decay time of the anode-cathode gap capacitance into the transmission line chis act.ristic impedance $R$ :

$t_{d}=R \times 8.05 \times 10^{-12} \frac{\mathrm{A}}{\mathrm{d}}$,

where $\mathrm{A}$ is the cathode area in square meters. We chose a detector cathode diameter of $1.39 \times 10^{-2} \mathrm{~m}$. an anode-cathode gap spacing of $1.27 \times 10^{3} \mathrm{~m}$, a bias voltage of $3 \mathrm{kV}$, and a $50 . \Omega$ characteristic impedance to match the oscilloscope. This gives a $10-90 \%$ risetime of 62 ps and an RC decay time constant of 53 ps. which should yield a detector with a FWHM of 73 ps.

To measure the risetime of the detector, we irradiated an aluminum slab target with a 1.2-j. 30-ps mode-locked Nd.YAG laser and measured the time history of low energy $x$ rays. The XRD used an aluminum cathode with a Kimfoil window that gave a peak response just below the carbon $\mathrm{K}$ absorption edge at $284 \mathrm{eV}$. A typical trace for $3 \cdot \mathrm{kV}$ detector bias and $1.27 \mathrm{~mm}$ anode cathode gap spacing is shown in Fig. 5 as recorded on a $5 . \mathrm{GHz}$ TMC.4 oscilloscope. "' This oscilloscope uses a cathode ray tube (CRT) built by the French Philips Compaily, with an electronics package buit and designed at LASL. Figure 6 shows how the 10-90\% risetime varies with detector voltage and anode-cathode gap separation. The data follow the $V^{-1 / 2}$ dependence of Eq. (1) to within the statistics of the data for both anode-cathode gap spacings after deconvolving the 66-ps risetime of the scope. However, the minimum 50-ps risetime is significantly shorter than the expected 62 ps. This may be due to a snialler anode-cathode gap spacing than desired or may result in part from the nonzero initial veolocity of the no-loss primary and Auger photoelectrons emitted from 

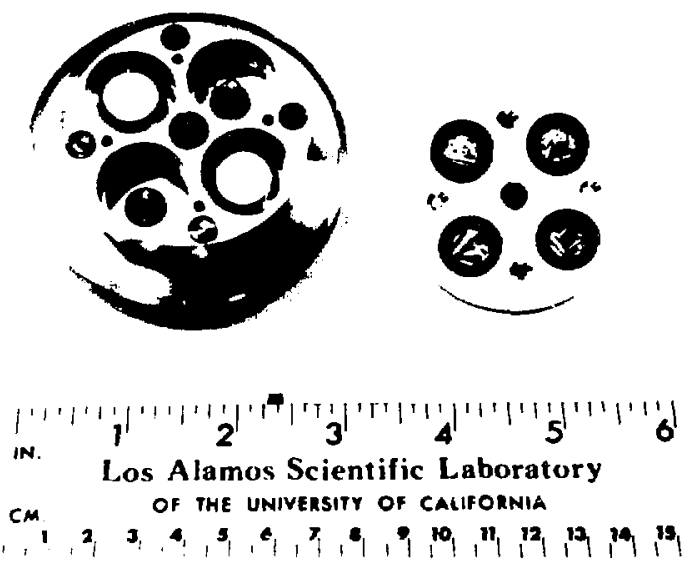

Fig. 3a.

The four felement XRD array with the filter window holder removed.

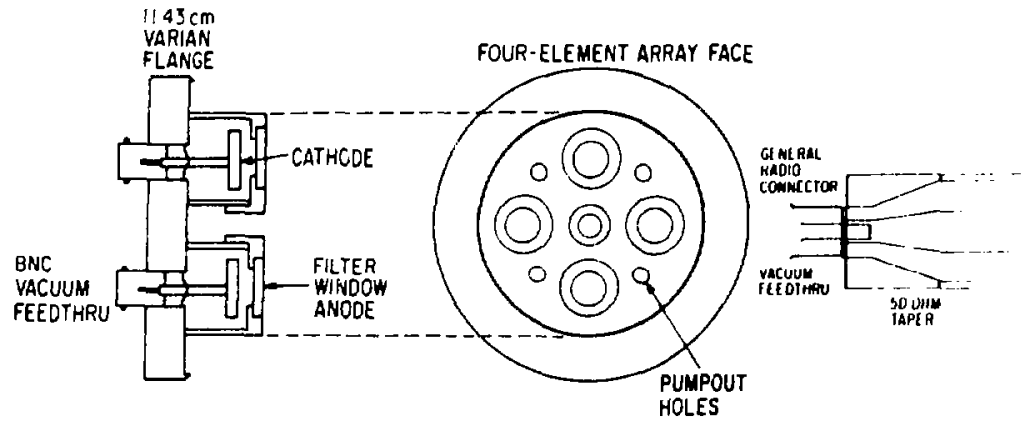

Fig. $3 b$.

Cross section of the four-element XRD array.

the photocathode. When we use the 50-ps measured risetime and the expected 53-ps RC decay time constants. the detector has a FWHM response tume of 65 ps.

To date, we have not directly measured the fall time of the detector. as $x$-ray sources with sufficient intensity and rapid turn off have not been available. The thermal decay of the low-energy $x$ rays in the laser-induced plasma is much longer than the expected fall time of the detector (Fig. 5). In the near future, we will use the 40-ps electron beam puise from the EG\&G, Santa Barbara Linac to generate a Cerenkov light pulse that we hope to measure with a vacuum ultraviolet (VUV) sensitive cesium iodide photocathode. This should give us our first measure of a rapidly falling signal.

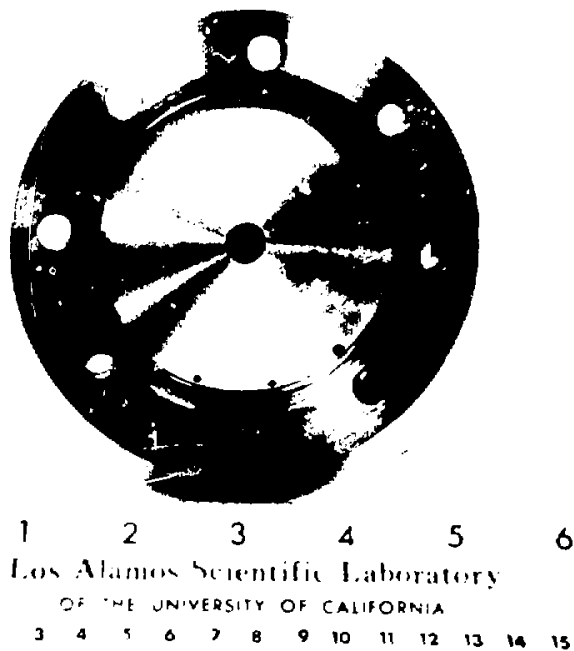

Fig. 4a.

The 5-GHz XRD.

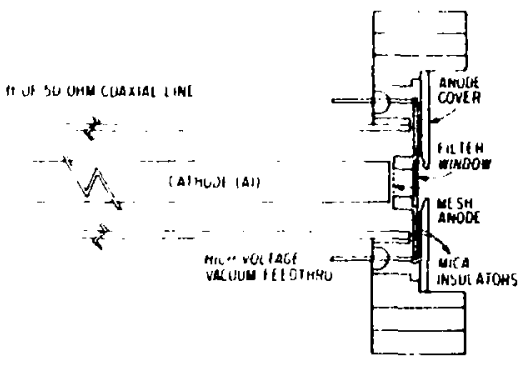

Fig. $4 b$.

Cross section of the 5.C.Hz XRD.

\section{THE CALIBRATION}

To make a useful detector system. it is necessary to measure the quanium efficiency of potential photocathodes from $20 \mathrm{eV}$ to $10 \mathrm{keV}$ and 10 measure the transmission of our filter windows below $100 \mathrm{eV}$. We have not attempted to prepare photocathodes of the highest purity and cleanliness: rather. like Cairns and Samson," our cathodes are commercially available "high purity," $>99 \%$, samples that have been dry machined to at least a 64 finish and routinely cleaned in freon and ethanol. The cesium iodide, scandium. and evaporated carbon surfaces were subsequently prepared by vaculim evaporation. Because cesium iodide is deliquescent. these 


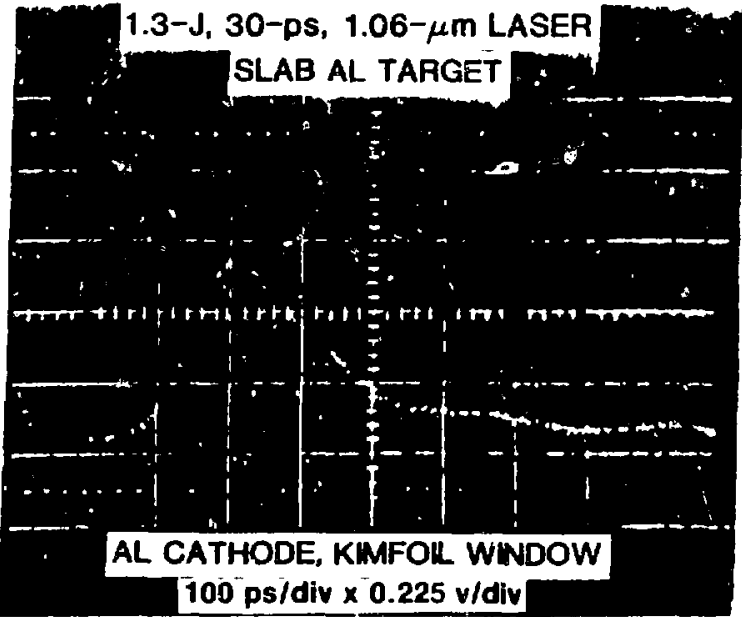

Fig. 9.

An oscilloscope trace showing the fass XRD risetime.

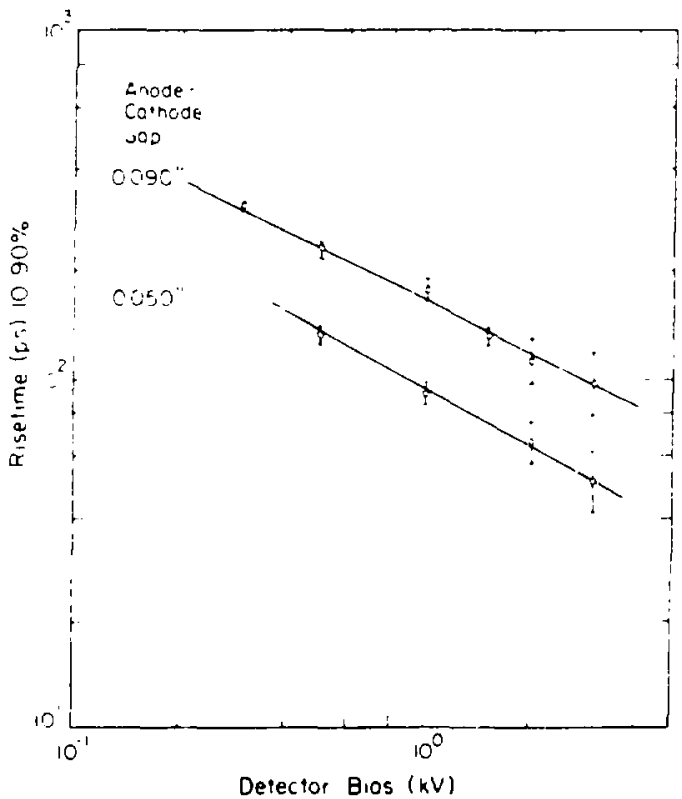

Fis. 6.

XRD risetirise vs anode-cathode gap voltuge and anode-cathode spacing.

surfaces are heat sealed in plastic bags under dry nitrogen and stored in a desiccator. Our primary interest is not to characterize elemental surfaces, but to prepare "practical" photocathodes that can be manufactured and reproduced easily and remain stable during experiments lasting up to several weeks.

We used three $x$-ray sources to cover the energy range from $25 \mathrm{eV}$ to $10 \mathrm{keV}$. The region from 25 to $250 \mathrm{eV}$ was measured at the synchrotron ultraviolet radiation facility (SURF II) of the National Bureau of Standards (NBS). The region from 1 to $10 \mathrm{keV}$ was measured with a fluorescent $x$-ray source at the LASL soft $x$-ray calibration facility, whereas the range from $250 \mathrm{eV}$ to $1 \mathrm{keV}$ was covered with an ultrasoft interchangeable anode $x$-ray source at the LASL soft $x$-ray calibration facility. Though each source has been described in detai] elsewhere. ${ }^{\text {th } 18}$ we briefly describe how the experiment was performed at each 「acility.

\section{A. SURF II}

The SURF II facility is an 83.8-cm-radius electron storage ring with a maximum beam energy of $250 \mathrm{Me} V$. As shown in Fig. 7, the radiation from the machine is dispersed by a toroidal grating monochromator with 2-A resolution and the dispersed beam passes through a 5-mm-diam aperture striking the photocathode. Data are aken in two energy regions. The first is from 25 to $76 \mathrm{eV}$ with a thin aluminum window to postfilter the beam and suppress second-order reflected photons. In this energy region, data are taken with electron beam energies of 140 and $250 \mathrm{MeV}$. The two beam energies allow us to correct accurately for second-or $\therefore$ and scattered photons across the entire energy iange. The second energy region is from 76 to $248 \mathrm{eV}$ using a thin polypropylene postfilter and a $250-\mathrm{MeV}$ electron beam. The cathodes are mounted in an NBS-designed diode with a cylindrical anode as shown in Fig. 8. The guard ring shown in this figure was a modification used at LASL to - fuce the anode leakage current. The photnelectric currents are measured with a vibrating reed electiometer and the data are reduced on-line by a microcomputer-controlled data acquisition system. Absolute dosimetry is performed with a noble gas double ionization chambe ${ }^{18}$ that is an integral part of the vacuum chamber.

The rear of the sample chamber is pictured in Fig. 9. The beam line is inclined with respect to the floor of the experimental hall and the synchrotron is $11 \mathrm{~m}$ in front of the chamber. The front handles hold the filters while the rear handles manipulate the diodes. Up to five cathodes and four filters can be measured in a single load.

The window material's photoelectric absorption coeffi. cients ase measured by inserting a filter in front of a 


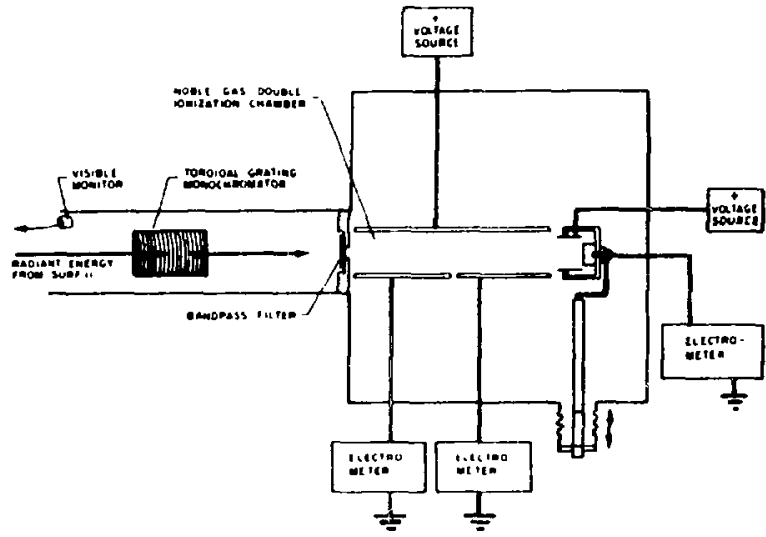

Fig. 7.

The $X$-ray ultraviolet (XUV) calibration beam line at the NBS SURF II radiation source.

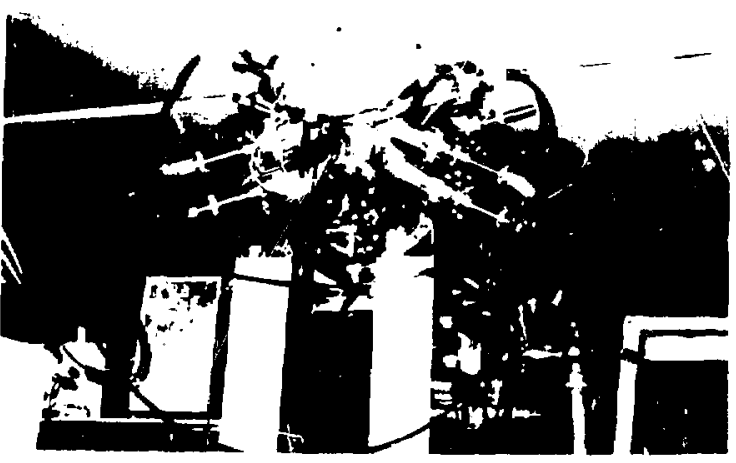

Fig. 9.

The end of the XUV calibration beam line at SURF II.

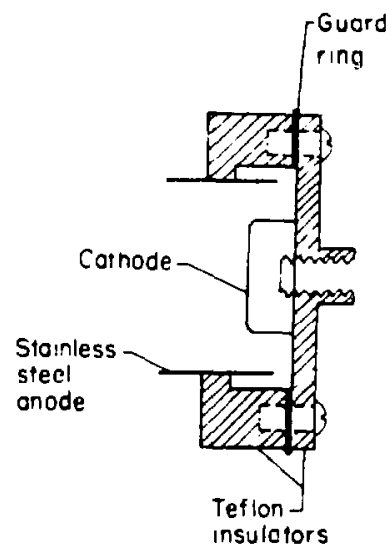

Fig. 8.

Cross section of the NBS cathode holder.

standard aluminum photocathode. By comparing measured diode currents with the filter in and the fitter out, the filter transmission is measured directly; and from the known thickness of the filter window, it is possible to determine its $x$-ray mass-absorption coefficient. The filters are biased po: :ively with respect to the diode to collect any stray electrons emitted from the filter. A lower limit of $1 \%$ transmission is measurable, with the limit set by the noise inherent in the cables that connect the diode to the electrometer.

\section{B. The LASL X-Ray Facility}

The $\mathrm{x}$-ray region from $250 \mathrm{cV}$ to $10 \mathrm{keV}$ is covered by two $x$-ray sources. The lower energy region from $250 \mathrm{eV}$ to $1.5 \mathrm{keV}$ is covered by the ultrasoft $x$-ray source shown in Fig. 10. The $x$-ray anodes are interchangeable to vary the characteristic line emission from the source and the detectors view the $x$-ray anodes directly. Source purity is controlled by postfiltration and maintaining low electron accelerating potentials. Dosimetry is performed with a flow proportionai counter and the photocathode currents are measured with a vibrating reed electrometer and recorded digitally through a voltape-to-frequency con. verter. The energy region from $1.5 \mathrm{lu} 10.5 \mathrm{keV}$ is covered with a fluorescent $x$-ray source (Fig. 11). A "Henke" $x$-ray tube is used to fluoresce various characteristic $x$-ray lines. Purity is controlled by varying the $x$-ray tube voltage and postifiltration of the fluorescent beam. Dosimetry is performed with a xenon ionization chambe: run at atmospheric pressure. ${ }^{20}$ The photocathode cur rents are recorded in the same manner as for the ultrasoft $x$-ray source.

In both systems, six diodes are mounted linearly in a slider that moves so that any of the cathodes will intercept the $x$-ray beam. A series of apertures and a thin filter window are used to intercept stray electrons. The cylindrical anode is maintained at $+50 \mathrm{~V}$. A separate shield electrode with an aperture that defines the $x$-ray beam is maintained at $+200 \mathrm{~V}$ (Fig. 12). The horizontal tube contains the array of cathodes and the 


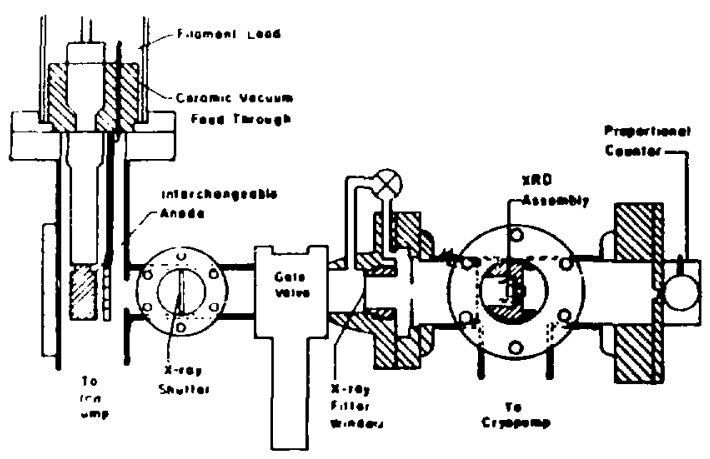

Fie. 10.

The LASL ultresoft x-ray source.

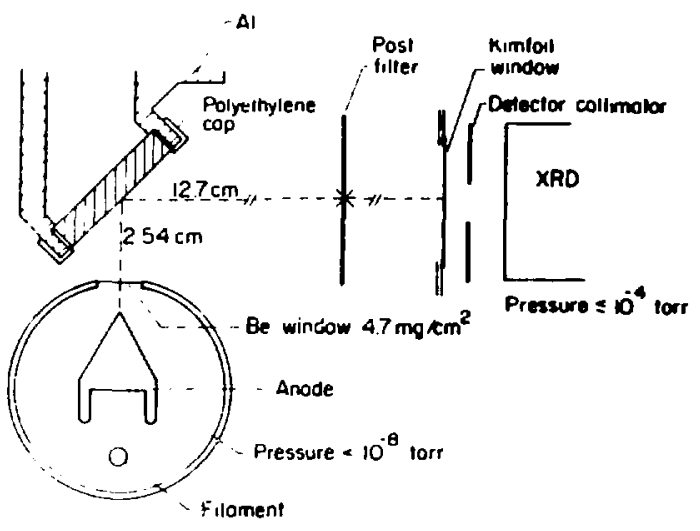

Fig. 11.

The LASL fluorescent $x$-ray source.

$x$ ray source and filter wheel are to the left. The ionization chamber is mounted just behind the cathodes to allow frequent dosimetry, and the data acquisition system can be seen in the background.

At the LASL and NBS facilities, the relative error of the measured currents is $>2 \%$. The errors on the measured quantum efficiencies of $\pm 10 \%$ are determined by the estimate of systematic errors from absolute dosimetry, beam siability, beam purity, and geometry.

\section{The Quantum Efficiencies}

The quantum efticiencies are compiled in Appendix A. Samples of aluminum, nickel, copper, chromium, $1000 \mathrm{~A}$

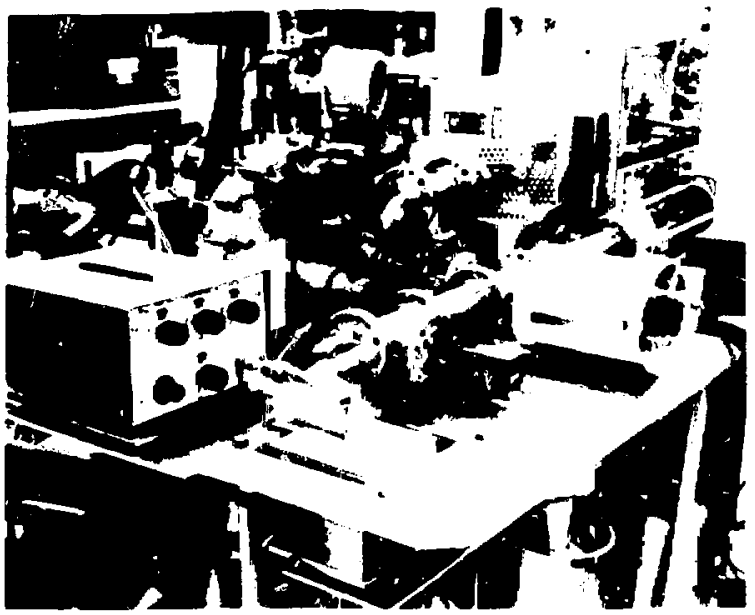

Fig. 12.

The LASL nuorescent x-ray source und data ecquisition system.

of gold evaporated on copper. 1000 A of carbon evaporated on copper, vitreous carbon, and vitreous carbon that was lightly abraded with sandpaper were measured over the entire energy range. We measured quantum efticiencies for $1000 \mathrm{~A}$ of cesium iodide evaporated on aluminum and $1000 \mathrm{~A}$ of scandium evaporated on aluminum from 1.5 to $10.5 \mathrm{keV}$. All of these measurements, except the titanium $L_{a}(452 \mathrm{eV})$. oxygen $K_{a}(525 \mathrm{eV})$, iron $L A(705 \mathrm{eV})$, and copper $L_{a}$ $(930 \mathrm{eV})$, were made within a few weeks of each other in January and February of 1978 and represent the quantum efliciencies of recently manufactured surfaces as described at the beginning of Section III. The titanium, oxygen, iron, and copper points were measured from March to April, 1978.

In Section IV, we quantitatively compare our results to Henke's model of total yield. ${ }^{13}$ However. here we merely note that in this model, total yield is proportional to $\mu(E)^{\star} E$, where $\mu(E)$ is the energy-dependent mass absorption coefficient. The quantum efficiencies shown in Appendix A follow this trend. The absorption edges of most materials are clearly visible. In addition, we see large discontinuities between the carbon $K_{a}$ data point at $277 \mathrm{eV}$ and the iron $\mathrm{L}_{\infty}$ point at $705 \mathrm{eV}$. This indicates that there are significant surface layers of carbon. nitrogen, or oxygen. The presence of such surface layers is not unexpected as we took no special precautions to suppress them during surface preparation and use. However, uncertainty in the exact cathode quantum efficiency in this region does not introduce serious uncertainty in the response of our detectors, because the 
filcer windows are chosen to strongly attenuate $x$ rays between the carbon and oxygen absorption edges.

An anomaly in the data is the unusually high quantum efficiency at carbon $K_{a}(277 \mathrm{eV})$ on the carbon cathodes; whereas, on the aluminum, nickel, copper, and gold data, the carbon data points match a continuation of the data from below to within the limits of error. The anomolously high response for carbon probably results from an overlap of the emission spectrum of the $x$-ray source with the low-energy side of the carbon absorption feature. which results in enhanced photon deposition and increased yield.

This reasoning also argues against carbon being the dominant surface contaminant that gives rise to the large jumps in the quantum efficiency of the aluminum, nickel, copper, and gold data between the carbon data point and the iron $\mathrm{L}_{n}$ data point. If a carbon surface layer were the major coutaminant. we would expect the same enhancement of the carbon $K_{n}$ data points as seen on carbon cathodes. Therefore, in the response curve for aluminum cathode XIRDs of Fig. 2. we show all the jump at the oxygen edge.

The evaporated cesium iodide surface is a particularly interesting cathode because its quantum efficiency is two orders of magnitude larger than aluminum and $\mathbf{3 0}$ times larger than gold from 1 to $10 \mathrm{keV}$. X-ray intensity from laser fusion plasmas typically fall very rapidly through this region and the low quantum cfficiency of metallic photocathodes make spectra immeasurable. We can record signals in this energy region with cesium iodide and will demonstrate some typical results in Section $V$.

\section{The Filter Window Absorption Coefficients}

In Appendix B, we compiled the photoelectric mass absorption coefficients for our filter windows. The samples were $7660 \mathrm{~A}$ of rolled aluminum, $272 \mu \mathrm{g} / \mathrm{cm}^{2}$ of Kimfoil with a 400-A aluminim surface layer, $70 \mu \mathrm{g} / \mathrm{cm}^{2}$ of polypropylene with a $\mathbf{5 0} \mathbf{A}$ nickel-chromium surface !iyer. and $33 \mathrm{\mu g} / \mathrm{cm}^{2}$ of Formvar. We measured two samples of each material. With the Kimfoil and polypropylene samples, we divided out the transmissivity of the metallic surface layers. The solid lines on the curves are the published coefficients of Henke and Ebisu. For aluminum below $100 \mathrm{eV}$, we used the DESY data." We also measured samples of $5000-A$, vacu. um-evaporated aluminum; however, we could not reliably remove the backing material and we have not used this type of window.
In general, the agreement between published absorption coefficients and out data is quite good. One exception is aluminum below the aluminum $\mathrm{L}_{2,3}$ absorption edge where the coefficients are anomolously high for low transmissions and low for high transmissions. This may result from nonuniforities in our rolled foils or inconsistencies with the published data. However. these curves represent the best transmission data of the filters we actually use; and these measurements were employed in generating the response curves shown in $\mathrm{Fi}_{t} 2$.

\section{E. Experiment and Model Comparison}

Henke et al. proposed a model of photoyield" where the electron yield per photon $Q(E)$ for incident photons of energy $E$ is

$\mathrm{QE}$ a $\mu(E) \times E \times \mathrm{fE})$ (electrons/photon).

where $\mu(E) \times E$ is the photon energy deposition pes undt distance near the surface of the cathode and $1(\mathrm{~F})$ is a slowly varying function of energy related to the efficiten cy of converting photo and Auger electron enrig! into secondary electrons.

To test tinis result, we plotted $Q(E) / \mu(E)^{*} E$ vs $F$ in Fig. 13 for the unabraded vitreous carhon. gold. and aluminum samples. The resultant curve is the cnergy dependence of $\mathrm{RE}$. The lines drawn through the data points of Fig. 13 are provided to guide the eve and do not represent a model of $f(E)$.

In general. $(\mathrm{E})$ is a slowis varyng function of ene? and the term $\mu(E)^{-E}$ accounts for most ol the twis or three orders of magnitude variation in quant :metric 10 . cy. For gold, $f(E)$ does not vary hy more than $2030 \%$ from $20 \mathrm{eV}$ io $10 \mathrm{KeV}$. A small anomaly is seen near $150 \mathrm{eV}$ at the $\mathrm{N}$ absorption feaiure and again at $1.8 \mathrm{heV}$ at the $M$ absorption edge. Aluminum show's the largest variation with a distinct jump at the aluminun $K$ absorption edge and large changes in $f(\mathrm{E})$ over the entire range of energies. The aluminum surface was modeled as $\mathrm{Al}_{2} \mathrm{O}_{3}$, and if we use a pure aluminum surface, the effect is even more pronounced. For the carbon surface. $($ E) is again slowly varying except at very low energies and with a $30 \%$ decrease from $100 \mathrm{eV}$ to $1.5 \mathrm{keV}$.

\section{REPRODUCIBILITY AND AGING}

\section{A. Reproducibility}

To avoid extensive calibration of every surface to be used in an experiment, we would like a technique for 


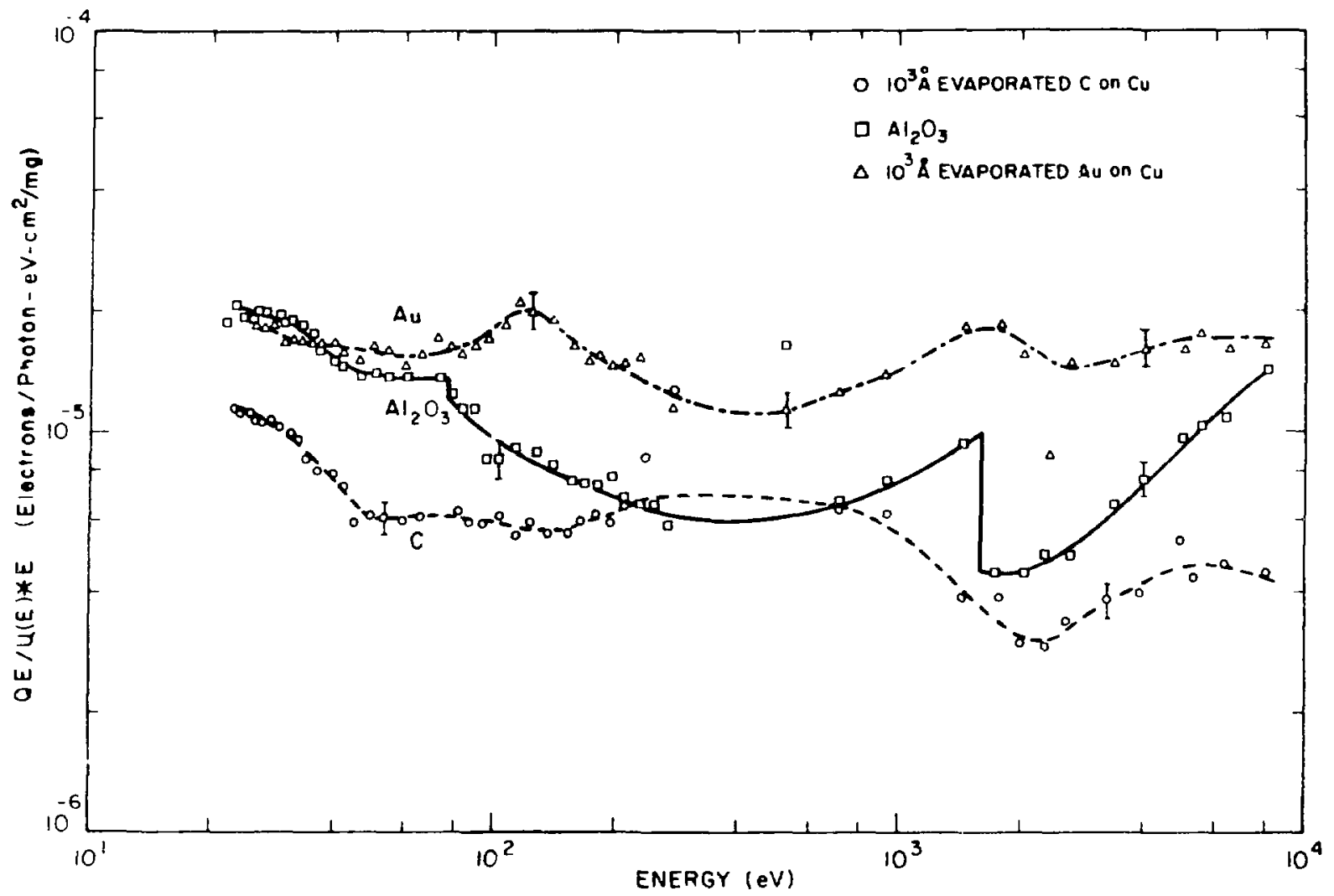

Fig. 13.

Energy dependence of f(E) (see text) vs energy for $\mathrm{Al}_{2} \mathrm{O}_{3}$, gold, and carbon.

producing surfaces with the same initial quantum efficiency. To test the reproducibility of our manufacturing rechnique, we prepared a set of five identical samples of 1100 series (>99\% pure) aluminum cathodes and calibrated them at $C K_{a}$. The samples were prepared in the usual way by dry machining the bulk material and cleaning with freon and ethanol. The results are shown in Table I. where the mean preshot quantum efficiency is $0.0267 \pm 0.0025$. This indicates that samples prepared from a single supply of material by a standard method will give reproducible quantum efficiencies to better than $\pm 10 \%$. Also, a sixth cathode of 1100 series aluminum produced from a different bulk sample had a quantum efficiency of 0.0294 , which is within one standard deviation of the other samples.

We also produced two identical samples each of aluminum. nickel, copper, evaporated gold, and evaporated carbnn. and calibrated them from 25 to 250 $\mathrm{eV}$ : their quantum efficiencies were identical to better than $\pm 10 \%$ across this entire range. Thus, it is possible to produce samples with identical quantum efficiencies to $\pm 10 \%$ by a simple standardized procedure.

\section{B. Effects of the Laser Fusion Environment}

We would like the detector sensitivity to remain unchanged in the environment where it will be used, and to be stable during a few weeks of experimentation. To test the effects of the laser fusion experimental environment. we prepared a set of five identical 1100 series aluminum cathodes with $272-\mu \mathrm{g} / \mathrm{cm}^{2}$ Kimfoil windows and one 6061 series aluminum alloy cathode. We then exposed these diodes to different numbers of laser shots with the cathodes remaining on the target chamber up to 2 wk. After $2 w k$, all diodes were calibrated. The average sensitivity decreased by $6.6 \%$. but there was no systematic effect related to time spent in the laser target chamber or number of target shots. Therefore, during the 2 wk and up to 10 target shots, we saw no effect 
TABLE I

\section{THE CHANGE IN SENSITIVITY OF ALUMINUM CATHODES AS A FUNCTION OF THE NUMBER OF TARGET SHOTS. CALIBRATION IS AT 277eV (C Ka).}

\begin{tabular}{ccccc} 
Cathode No. & $\begin{array}{c}\text { Material } \\
\text { (Al) }\end{array}$ & No. of Shots & $\begin{array}{c}\text { Preshot } \\
\text { Calibration } \\
\text { (Quantum Effi- } \\
\text { ciency) }\end{array}$ & $\begin{array}{c}\text { Postshot } \\
\text { Calibration } \\
\text { (Quantum Effi- } \\
\text { ciency) }\end{array}$ \\
\hline 1 & 606 I-T6 & Control & 0.025 & 0.023 \\
2 & $1100-$ H14 & Control & 0.028 & 0.027 \\
3 & $1100-H 14$ & $0^{\mathrm{a}}$ & $\mathbf{0 . 0 2 7}$ & $\mathbf{0 . 0 2 5}$ \\
4 & $1100-\mathrm{H} 14$ & 1 & $\mathbf{0 . 0 2 4}$ & $\mathbf{0 . 0 2 2}$ \\
5 & $1100-\mathrm{H} 14$ & 3 & $\mathbf{0 . 0 2 5}$ & $\mathbf{0 . 0 2 4}$ \\
6 & $1100-\mathrm{H} 14$ & 10 & $\mathbf{0 . 0 3 0}$ & $\mathbf{0 . 0 2 8}$
\end{tabular}

apumped out with the laser chamber.

that can be ascribed to the laser fusion experimental environment.

This does not mean. however. that cathodes can be prepared and used for long periods of time without sgnificant changes in sensitivity. We merely have established that we can produce surfaces with quantum efficiencies that are identical to $\$ 10 \%$ that can be used for short periods of time with less than $10 \%$ change in absolute sensitivity.

We also monitored the condition of the filter windows. Although laser target shots deposit insufficient material to significantly alter the filter window transmissivity, the hot plasma and occasioral pieces of shrapnel can degrade the filters. Therefore. it is necessary to inspect the filter windows freyuently and change them at least as often as the cathodes.

\section{Effects of Cathode Aging}

We monitored the long term change in cathode sensitivity by recalibration of the aluminum, evaporated gold, and evaporated carbon samples over the following year. The initial set of cathode surfaces described in Section III.C. were first calibrated during January through February 1978 and used in a laser fusion experiment in May when each detector was exposed to six shots of the GEMINI $\mathrm{CO}_{2}$ laser-irradiating neon-filled glass ruicroballoons.

We also maintained control samples of the aluminum, evaporated gold, and evaporated carbon surfaces at
NBS. Here we discuss the effects of long-term aging on the control cathodes and then relate these results to the changes seen on the cathodes that were used at LASL.

We recalibrated the cuantum efficiencies of all surfaces from 75 to $250 \mathrm{eV}$ in July of 1978. The control samples of aluminum and evaporated carbon were maintained in the sample chamber at $10^{-8}$ torr during the interim and their efficiencies were unchanged from 75 to $250 \mathrm{eV}$ as shown in Figs. 14a and b. The data points for the January 1978 calibration are represented as circles and the crosses are the July calibration. Thus, these surfaces do remain stable when maintained in a high-purity ultrahigh vacuum system. On the other hand, the gold cathode shown in $\mathrm{Fig} .14 \mathrm{c}$ was left in ambient air during this time and shows significant change in quantum efficiency from 75 to $250 \mathrm{eV}$. In particular. the size of the $\mathrm{N}$ absorption feature at $200 \mathrm{eV}$ has been suppressed.

Because of experimental exigencies, it was not possible to finish the recalibration of all surfaces from 25 to $75 \mathrm{eV}$ until December 1978. During the interim, all samples were left out of the vacuum system at NBS. These data from 25 to $75 \mathrm{eV}$ are also plotted in Figs. 14a, b, and c. The carbon surface, which had been stable while in the vacuum system, now changed. The gold surface also shows significant change from its January 1978 calibration. However, we do not see a significant discontinuity at $75 \mathrm{eV}$ between the July and December calibrations. This may indicate that the additional change in the gold surface in the second 6 months was small compared tc the first 6 months. The aluminum surface did not show 


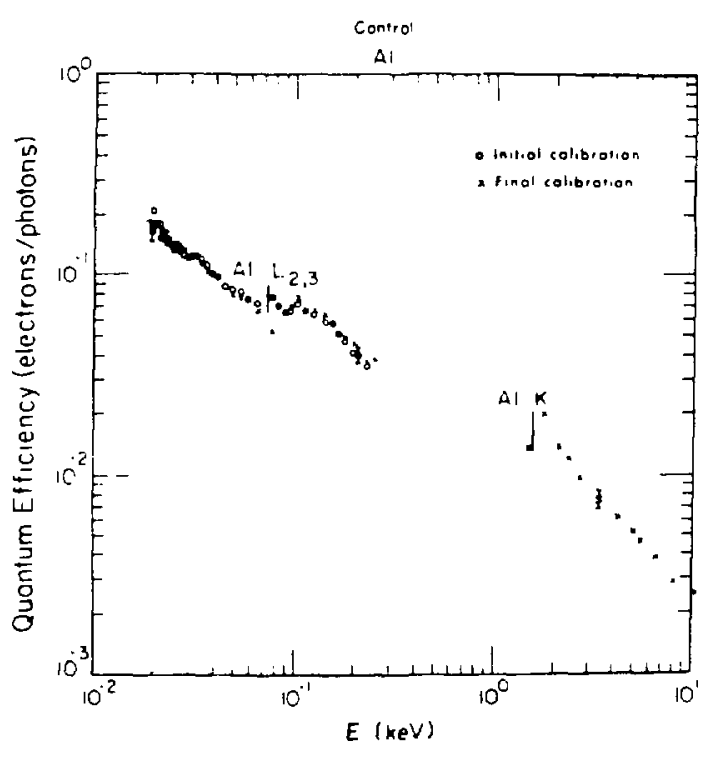

Fig. 14a.

Initial and final calibration of the control aluminum sample.

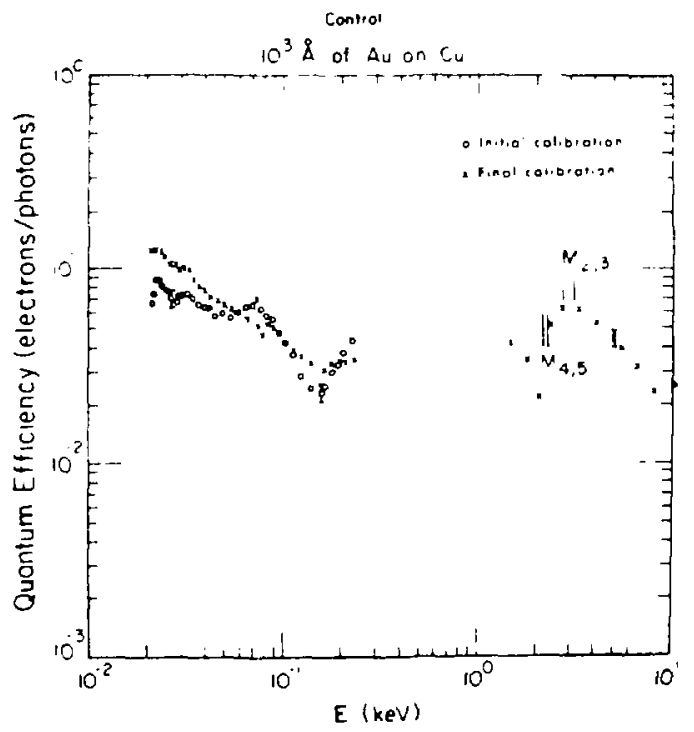

Fig. 14c.

Initial and final calibration of the control evaporated gold sample.

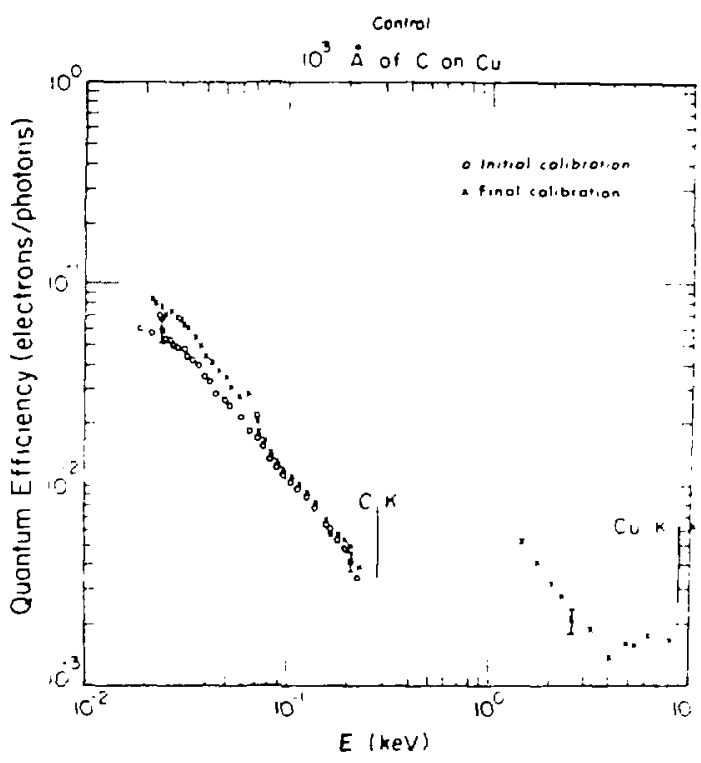

Fig. 14b.

Initial and final calibration of the control evaporated carbon sample.

significant changes from January to December 1978. Thus. the control aluminum surface appears to have quickly achieved a stable surface layer after manufacturing and did not change appreciably thereafter.

The aluminum. evaporated gold, and all the carbon samples that were returned to LASL in January 1978 were recalibrated from 25 to $250 \mathrm{eV}$ with the control samples, and all samples were calibrated from 1 to 10 keV in March 1979. The samples that were used at LASL all showed changes in their quantum efficiency by as much as a factor of 2 or 3, except for abraded vitreous carbon, which remained essentially unchanged. These results are plotted in Figs. 15a through e. As with the evaporated carbon control sample, the evaporated carbon sample used at LASL also increased in quantum efficiency. The same is true of the two evaporated gold samples. The aluminum sample that was used at LASL showed a decrease of $50 \%$ in sensitivity. The unabraded vitreous carbon sample showed a large increased quantum efficiency, although the abraded vitreous carbon sample did not change. Indeed, all the surfaces changed 

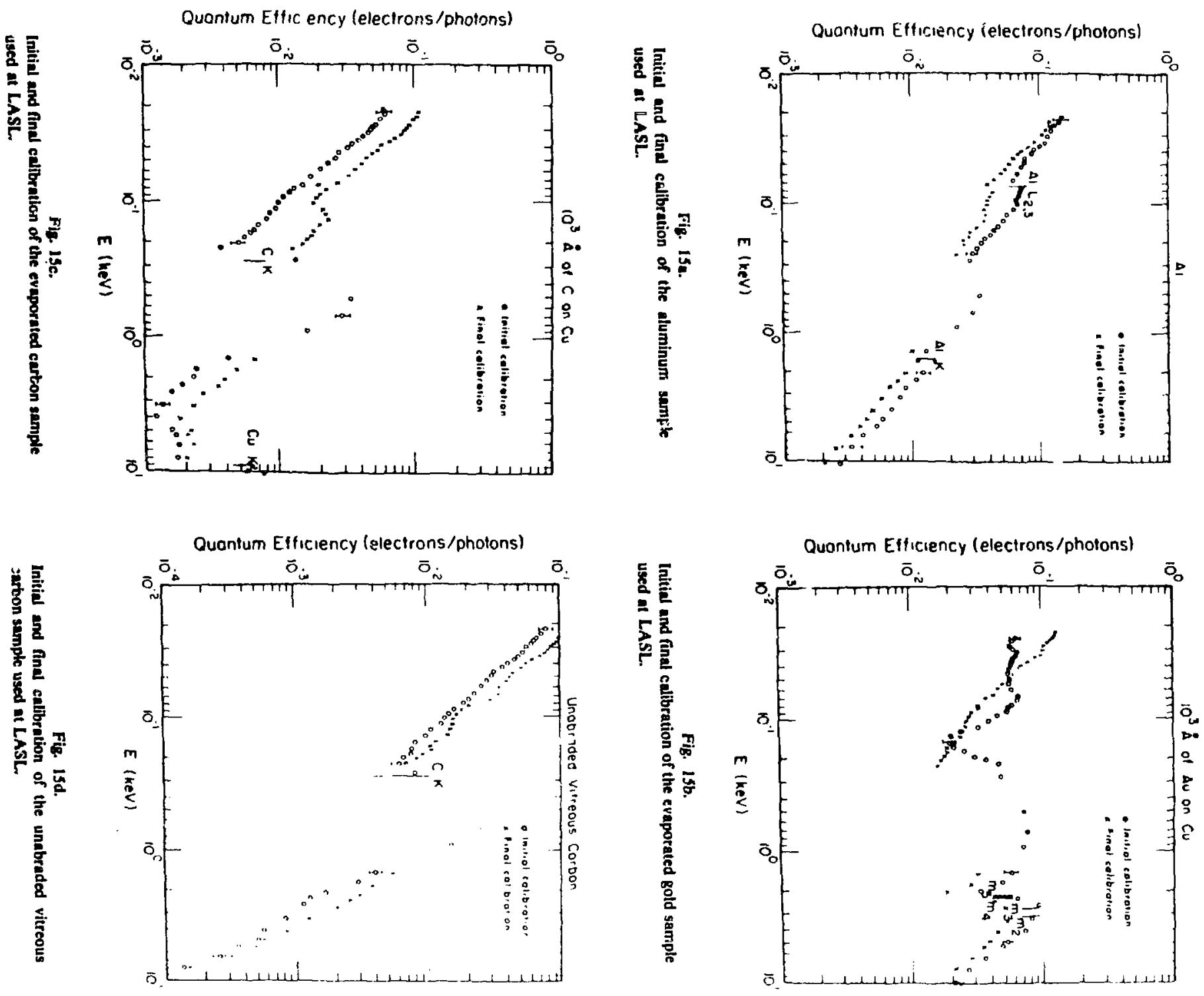


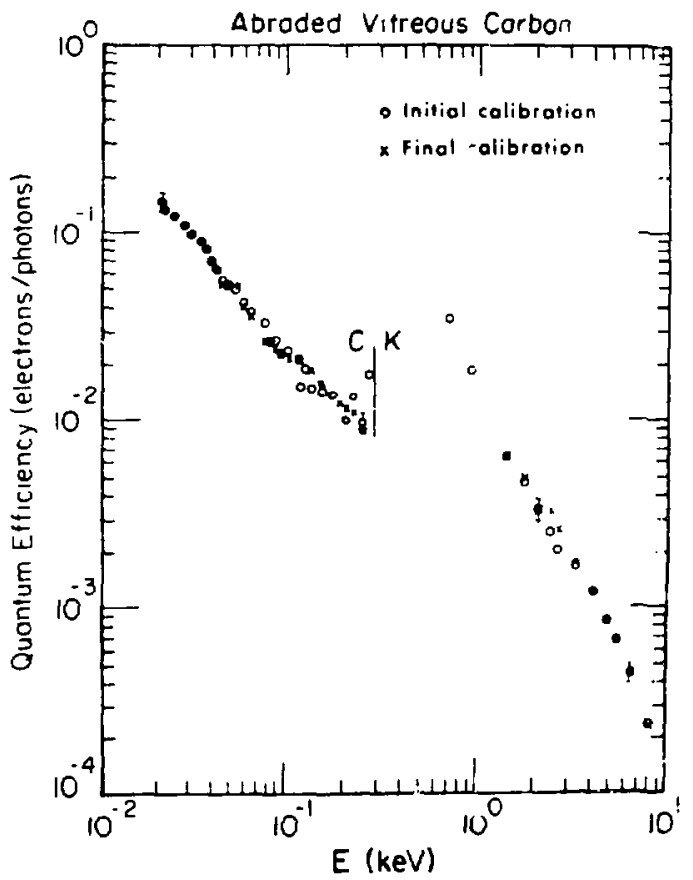

Fig. 15e. Initial and final calibration of the abraded vitreous carbon sample used at L.ASL.

so that they exhibit fewer features associated with the characteristic cathode material and tend toward a median quantum efficiency.

We conclude from this study that the aging of the cathode surfaces is a complicated time-dependent process with time constants of months and quantum efficiency changes of a factor of 2 or 3 . depending on the surface type and the photon energy. However, based upon the results of Section IV, it does appear possible to prepare identical aluminum surfaces to $\pm 10 \%$ that can be used for short periods of time in the laser fusion environment with less than $\pm 15 \%$ uncertainty in the absolute detector response. However, to measure absolute fluxes $v$ ith XRDs, one must be extremely careful to either change cathodes and windows requently or to recalibrate. Alternatively, based upon the stable response of the control sampes when they are left in an ultrahigh vacuum envircnment, it may be possible to build stable detectors with small integral pumps and a gate valve to maintain the surfaces in a clean environmont except during a shot. This suggestion will be the subject of further study.

\section{v. APPLICATIONS}

\section{A. Time-Integrated Ultrasoft X-Ray Spectra}

We used the miniaturized four-element XRD array discussed in Section Il to measure time-integrated ultrasoft x-ray spectra for 200- $\mu \mathrm{m}$-diam D-T filled glass microballoons imploded with the LASL eight-beam $\mathrm{CO}_{2}$ laser, HELIOS. Typical total beam energies and powers for tisese shots are $4 \mathrm{~kJ}$ at $4 \mathrm{TW}$. The XRD channels all used aluninum cathodes with windows of $7600-\mathrm{A}$ aluminum, $272-\mu \mathrm{g} / \mathrm{cm}^{2}$ Kimfoil $+400-A$ aluminum, $7600-\AA$ aluminum $+1-\mu \mathrm{m}$ beryllium, and Kimfoil + 2- $\mu \mathrm{m}$ beryllium. which yielded peak sensitivities at 30-70, $277.750 \mathrm{eV}$, and $\mathrm{l} \mathrm{keV}$, respectively. The spectra werc then generated by dividing the total integrated charge by the detector sensitivity and the energy width of the channels. The two low-energy channels were corrected for their high-energy response by subtracting the measured charge in the high-energy channels. This correction was usually less than $20 \%$ of the total charge in the low-energy channel. The final spectra were then normalized per joule of incident $\mathrm{CO}_{2}$ laser energy. The results are plotted in Fig. 16.

It is necessary to provide an electron sweeper in front or the derectors, especially with $\mathrm{CO}_{2}$ irradiated plasmas. The sweeper will stop the high-energy electrons emitted from the plasma from striking the cathode and causing undershoot in the traces. For our purposes, the sweepers are 1- to $2-\mathrm{kG}$ magnetic fields over a $5-\mathrm{cm}$-long path apertured to $1 \mathrm{-cm}$ diameter at both ends. The interior of the sweeper is lined with a low- $Z$ material to suppress bremsstrahlung. RF-microwave interference is suppressed with grounded wire meshes placed across the sweeper apertures.

\section{B. Time-Resolved X Rays}

Figure 17 is a montage of several applications of the fast XRD. The upper left photo shows an $X-r a y$ signal taken with an aluminum cathode and Kimfoil window on an aluminum slab target irradiated with a $30-\mathrm{ps}, 1.3-\mathrm{J}$ Nd-YAG laser pulse. The signal is recorded with the 5-GHz TMC-4 oscilloscope at 100-ps/div sweep time. The trace demonstrates the risetime of the detector. However, notice the relatively long tail of the trace while the plasma cools. The upper right trace is the same channel recorded on the GEMINI $\mathrm{CO}_{2}$ laser with a 1-ns laser pulse. The time scale is $1 \mathrm{~ns} / \mathrm{div}$ and again the $\mathrm{x}$-ray plasma emission lasts much longer than the laser pulse. 


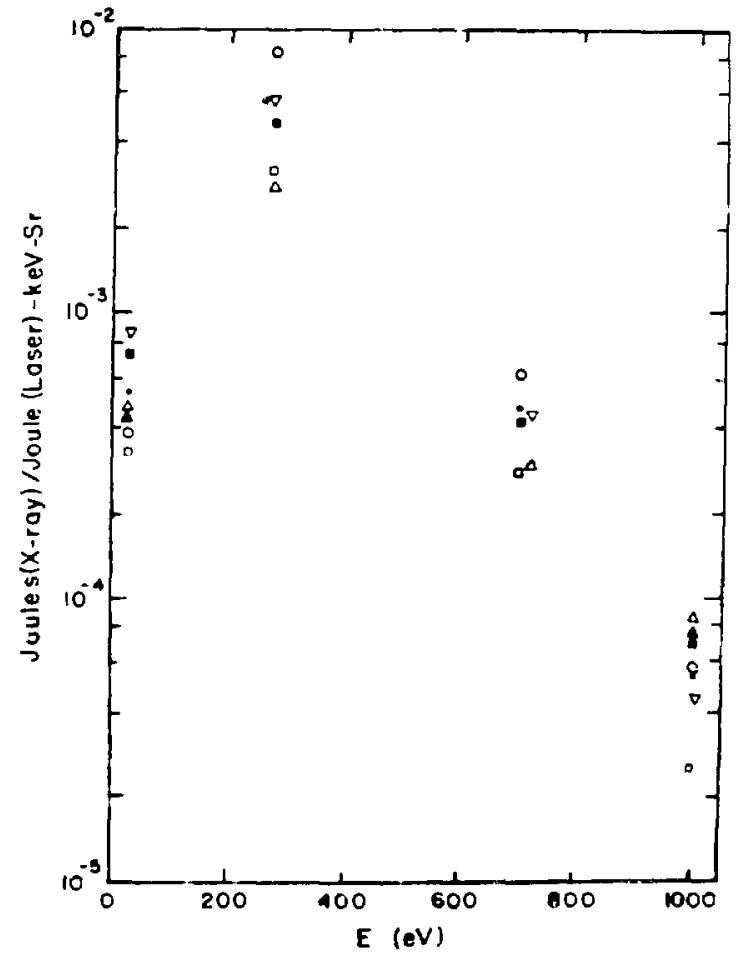

Fig. 16.

Typical x-ray spectra from 200-um-diam D-T filled glass microballoons imploded with the LASL HELIOS laser.

The lower left-hand picture is a $200-\mu \mathrm{m}$-diam, nickel-coated, unfilled glass microballoon imploded with a 0.1-TW, 300-ps, two-beam Nd-YAG laser. The detector utilized a cesium iodide cathode with a $0.92-\mathrm{mg} / \mathrm{cm}^{2}$ chlorine window $+12 \mu \mathrm{m}$ of beryllium that gave a peak response at about $1.0 \mathrm{keV}$. The $x$-ray pulse at this energy follows the laser pulse much more closely but still appears to have a somewhat extended late-time emission.
The lower right-hand picture was taken with the two-beam GEMINI $\mathrm{CO}_{2}$ laser that irradiated a titanium square $200 \mu \mathrm{m}$ on a side by $25 \mu \mathrm{m}$ thick. The detector used a cesium iodide photocathode with an $11.5-\mathrm{mg} / \mathrm{cm}^{2}$ titanium filter window, which yields a channel with maximum response just below the titanium $\mathrm{K}$ absorption edge at $4.5 \mathrm{keV}$. The $\mathrm{x}$-ray pulse is no wider than the iaser pulse at this $x$-ray energy.

These results are a small sample of the data va have gathered to date. The cesium iodide and other high-sensitivity photocathodes are particularly promising as they allow us to extend the use of these detectors well above $1 \mathrm{keV}$. Conversely, we can use the increased efficiency of the halide cathodes to recover detector efficiency lost in spatially or energy-dispersive applications. X-ray diodes ar: very useful tools for measuring time resolved $x$-ray spectra. The detector's response is reproducible if cathoue preparation is standardized and they can be used for short periods of time in ihe relatively clean cnvironment of laser fusion experiments without serious changes in sensitivity. However, it is essential that the sensitivity of these detectors be monitored frequently while in use to ensure their absolute calibration.

\section{ACKNOWLEDGEMENTS}

We would like to acknowledge the help of Douglas Lier and Thomas Elsberry of LASL in performing many of the calibrations. We also acknowledge Peter Lyons of LASL and Burton Henke of the University of Hawaii for their many useful conservations. Lonnie Hocker of EG\&G. Santa Barbara was particularly helpful in the design and characterization of our fast $x$-ray diode and David Van Hulsteyn of LASL helped in the risetime measurements. 

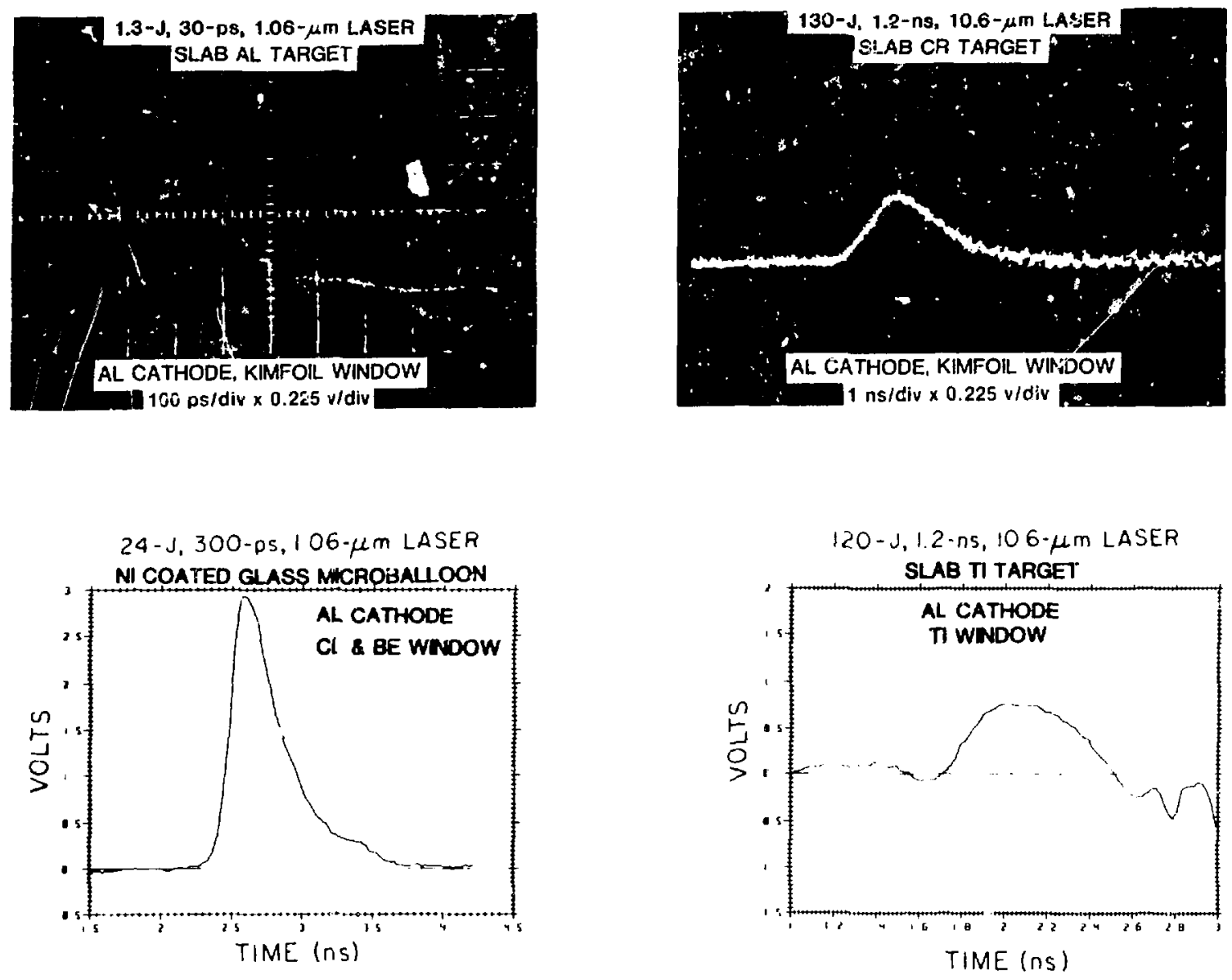

Fig. 17 .

Typical time-resolved $\mathrm{x}$-ray pulses. 


\section{REFERE NCES}

I. J. L. Gaines, H. N. Kornblum, and V. M. Slivinksy, "Lo"y Energy X-Røy Detectors for Laser Fusion Tariets," Lawrence Livermore Laboratory report UCRL 75:87 A (1974).

2. E. J. T. Burns, "Soft X-Ray Vacuum Ultraviolet Diagnostics of High Density, High Temprature Plasinas at the Air Force Weapons Laboratory," Ad?. X-Ray Anal. $18117(1974)$.

3. R. H. Day, "Sub-Kilovolt X-Ray Diode for Laser Fusion Plasma Diagnostics," Bull. Am. Phys. Soc. 22. 1196 (1977).

4. R. B. Caims and J. A. R. Samson, "Metal Photocathodes as Secondary Siandards for Absolute Intensity Measurements in the Vacuun Ultraviolet," J. Opt. Soc. Am. 56, 1558 (1966).

5. E. B. Saloman, "Typical Photoefficiency Between $20.250 \mathrm{eV}$ of Windowless XUV Photodiodes with Tungsten and Anodized Aluminum Oride Hotocathodes," Appl. Opt. 17, 1489 (1978).

6. J. L. Gaines and R. A. Hansen, "X-Ray Induced Electron Emission from Thin Gold Foils," J of Appl. Phys. 47, 3923 (1976).

7. L. G. Eliseenko, V. N. Schemelev, and M. A. Rumsh, "Quantum Yjelds of the Surface X-Ray Photoeffect at 1-10 A." Zh. Tekh. Fiz. 38, 175 (1968), Sov. Physics-Tech. Phyciss 13, 122 (1968).

8. H. J. Hagemann. W. Gudat, and C. Kunz, "Optical Constants From the $F$ ar Infrared to the $\mathrm{X}$-Ray Region: $\mathrm{Mg}, \mathrm{Al}, \mathrm{Cu}, \mathrm{Au}, \mathrm{Bi}, \mathrm{C}$, and $\mathrm{Al}_{2} \mathrm{O}_{3}, "$ Deutches Elektronen-Synchrotron report DESY SR - 74/7 (1974).

9. B. L. Henke and E. S. Ebisu, "Low Energy X-Ray and Electron Absorption Within Solids," Adv. X-Ray Anal. 17, 150 (1973).

10. W. J. Viegele, E. Briggs, L. Bates, E. M. Henry, and B. Bracewell, "X-Ray Cross-Section Compilation from $0.1 \mathrm{keV}$ to $1 \mathrm{MeV}$," Kaman Sciences Corporation report $\mathrm{KN}-71-43 \mathrm{I}(\mathrm{R})(1971)$.
11. E. Storm and H. I. Israel, "Photon Cross Sections from $i \mathrm{keV}$ to $100 \mathrm{MeV}$ for Elements $Z=1$ to $Z=$ 100," Nuc. Data Tables 7,565 (1970).

12. W. H. McMaster, N. K. Del Grande, J. H. Mallett, and J. H. Hubbell, "Compilation of X-Ray Cross Sections," Lawrence Livermore Laboratory report UCRL 50174 (1969).

13. 8. L. Henke, J. A. Sinith, and D. T. Atwood, "0.1-10 keV X-Ray Induced Electron Emissions from Solids-Models and Secondary Electron Measurements," J. Appl. Phys. 48, 1852 (1977).

14. G. Beck. "Photociude and Holder with 60-psec Response Time," 77 Rev. Sci. Instrum. 47, 849 (1976).

15. E. J. McLellan and J. S. L insford, "A Single Sweep 5-GHz Oscilloscope-Detector Combination for $\mathrm{CO}_{2}$ 'aser Pulse Measurements," Proc. Conf. Laser E.lzineering and Applications, Washington, $\mathrm{D}$. (1977).

6. E. B. Saloman and D. L. Ederer, "Absolute Radiometric Calibration of Detectors Between 100-600 A," Appl. Opt. 14, 1029 (1975).

17. P. B. Lyons and D. W. Lier, "Fabrication and $X$-Ray Calibration of Thin Plastic Scintillator Detectors," JEEE Trans. on Nuc. Sci. NS- 22, 88 (1975).

18. P. B. Lyons, R. H. Day. D. W. Lier, and T. L. E sberry, "Sub-keV X-Ray Calibration of Plastic Scintillators," Proc. ERDA X- and gamma-Ray Symp., Ann Arbor. Michigan, paper number 760539, 79 (1979).

19. J. A. R. Samson, "Absolute Intensity Measurements in the Vacuum Ultraviolet," J. Opt. Soc. Am. 54, 6 (?964).

20. P. B. Lyons, J. A. Baran, and J. H. McCrary, "A Total Absorption Ionization Chamber for 1.5-10 ke'V X-Rays," Nucl. Instrum. Methods 95, 571 (1971). 
APPENDIX A

COMPILATION OF QUANTUM EFFICIENCIES

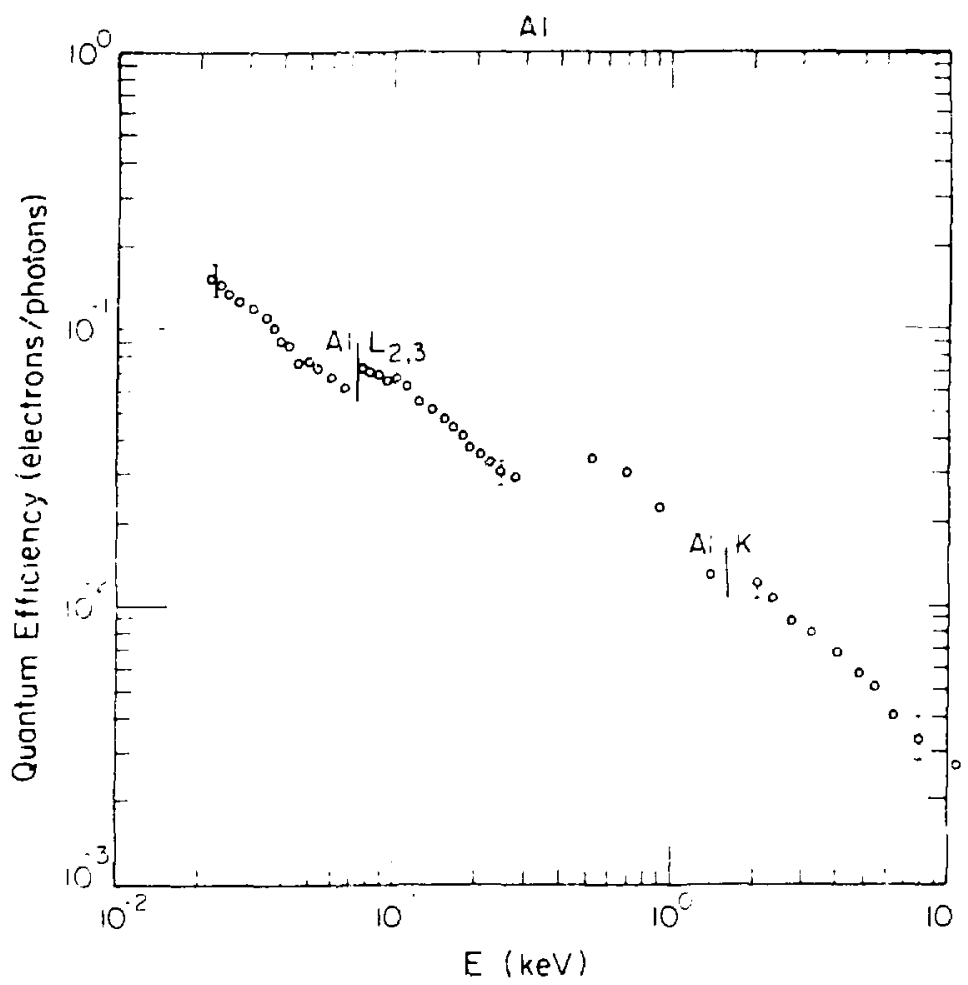

Fig. A-1.

Measured quantum efficiency of aluminum.

Fig. A - 2 .

Measured quanium efficiency of nickel.

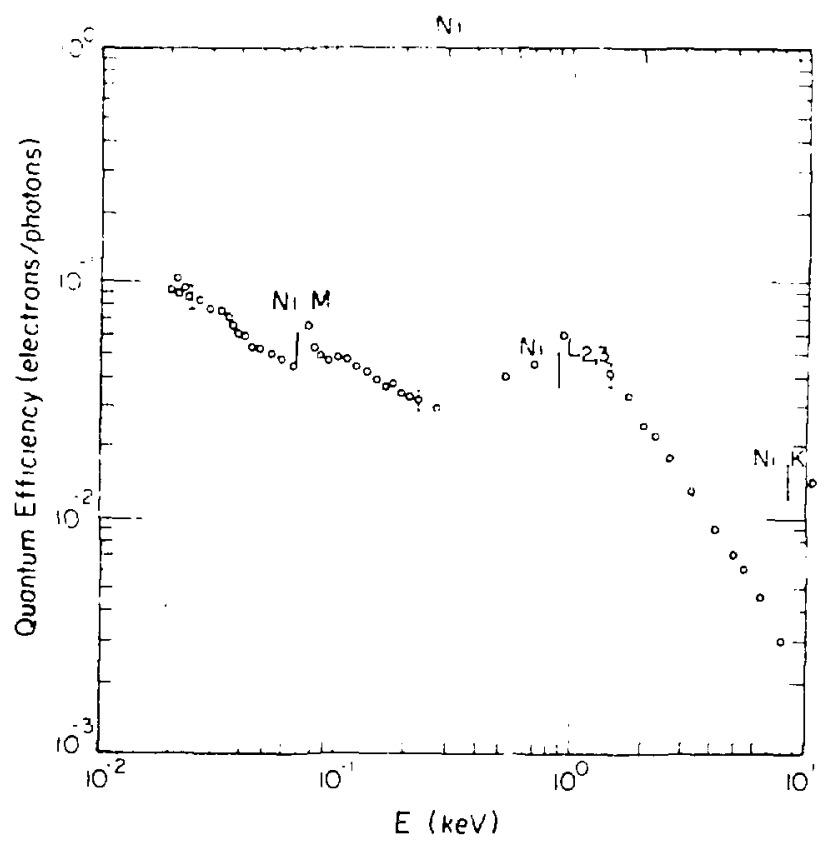




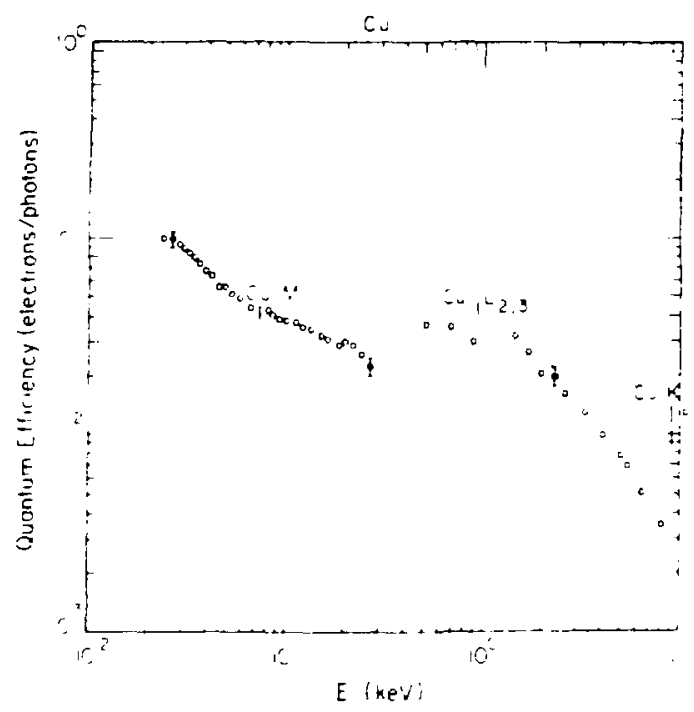

Fig. A-3.

Measured quantum efficiency of copper.

Fig. A-4.

Messured quantum efficicncy of evaporated gold on copper.

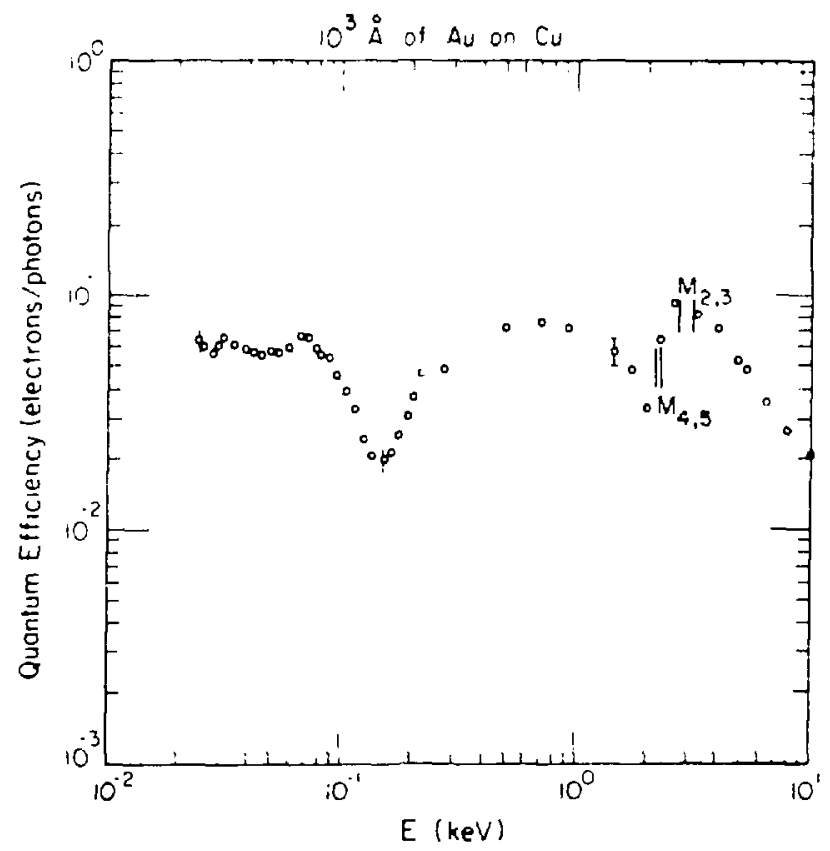




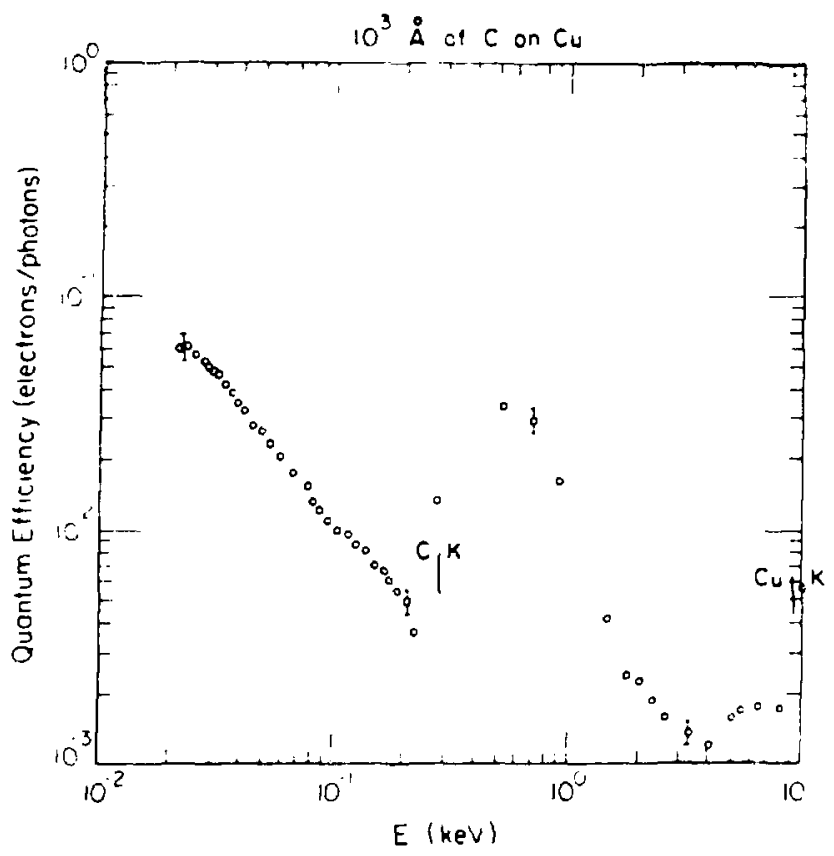

Fig. A-s.

Measured quantum eficiency of evaporated carbon on copper.

Fig. A-6.

Measured quantum efficiency of unabraded vitreous carbon.

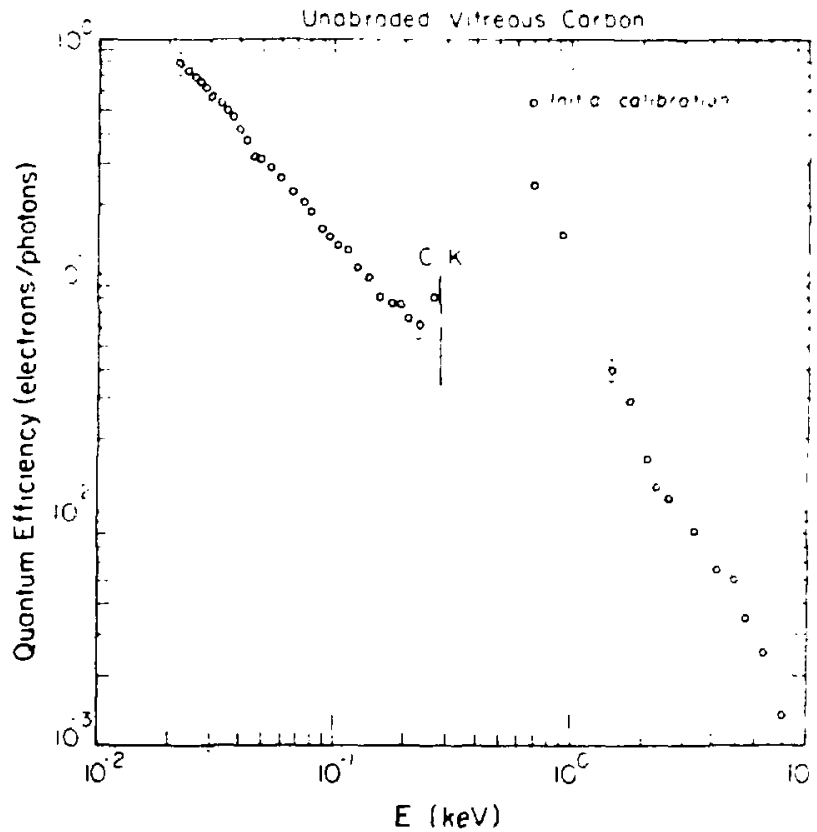




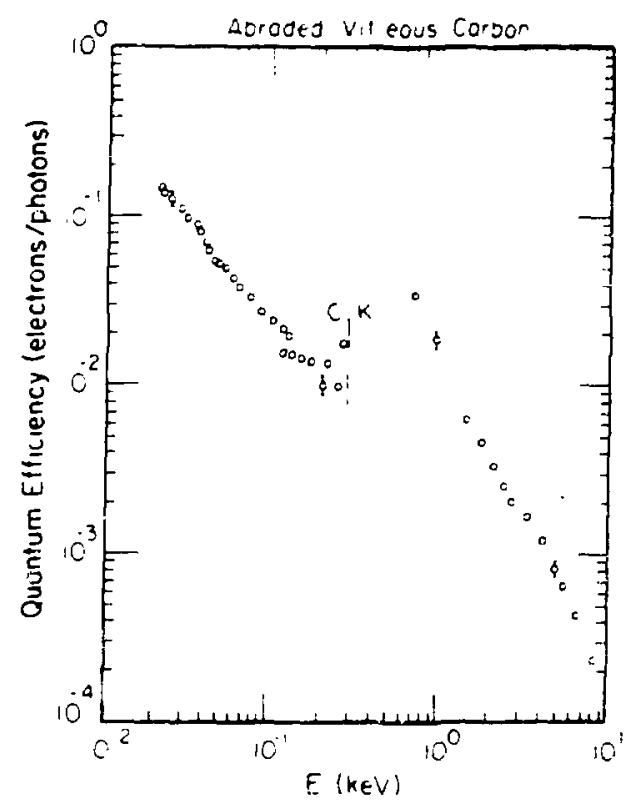

Fig. A 7.

Measured quentum efliciency of abraded vitreous carbon.

Fig. A.8.

Measured quantum efileiency of chromium.

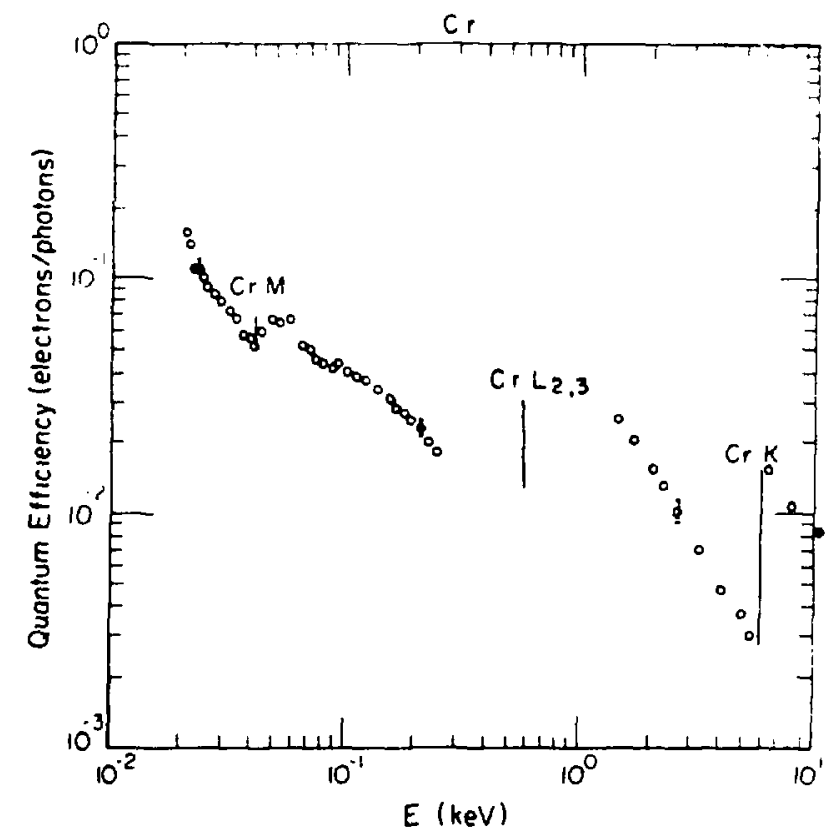




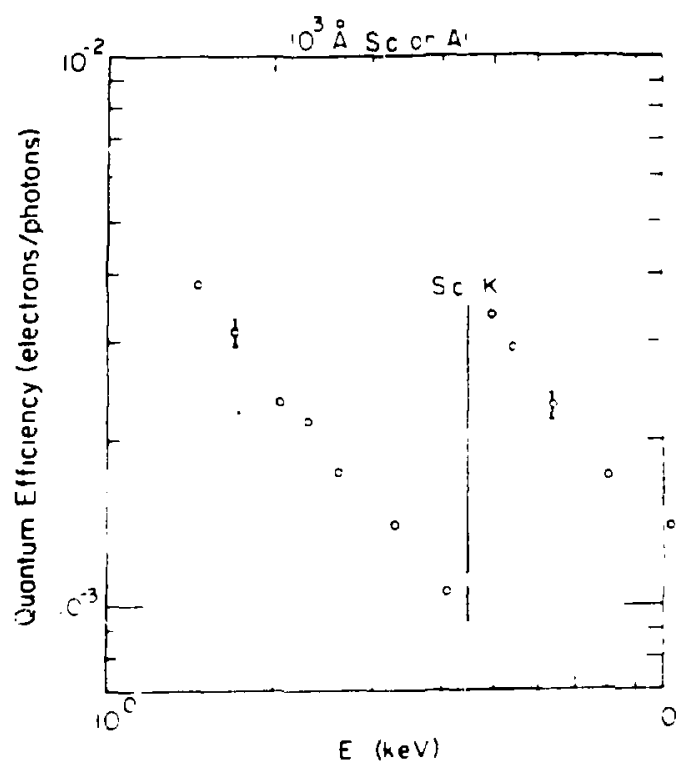

Fig. A.9.

Measured quantum efficiency of e:sporated scandium on aiumisum.

Fig. A.10.

Measured quantum efficiency of evaporated cesium on aluminum.

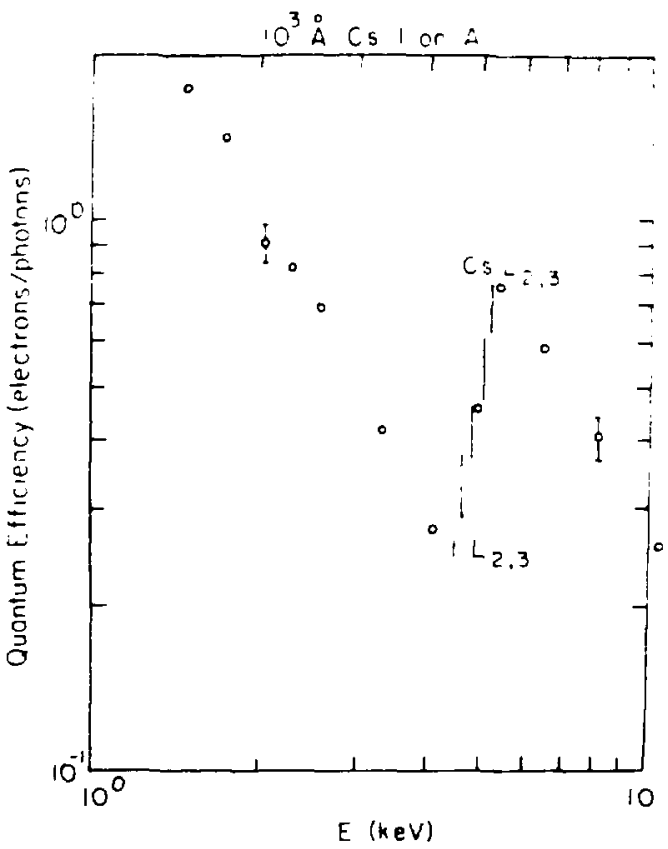




\section{APPENDIX $B$ \\ COMPILATION OF ABSORPTION COEFFICIENTS}

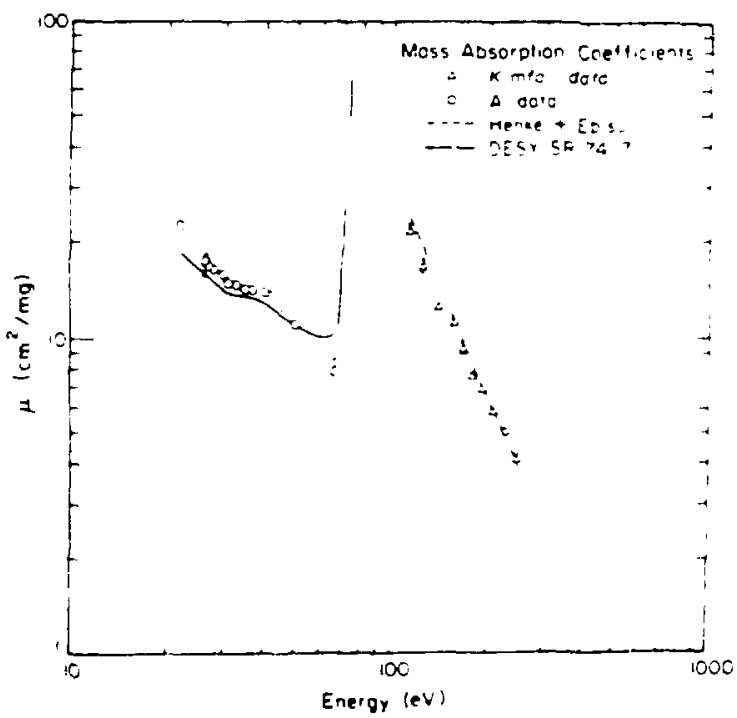

Fig. 8-1.

Photoelectric mass absorption coeficients of rolled aluminum and Kimfoil.

Fic. B-2.

Photoelectric mass absorption coefficients of Formvar and polypropylene.

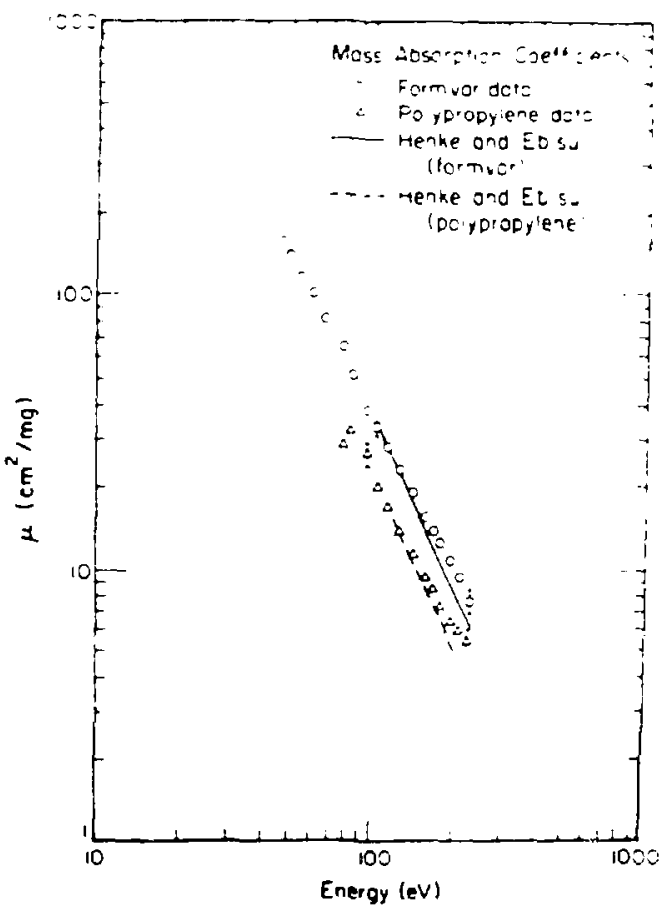

